NBER WORKING PAPER SERIES

\title{
DAYS TO COVER AND STOCK RETURNS
}

\author{
Harrison Hong \\ Weikai Li \\ Sophie X. Ni \\ Jose A. Scheinkman \\ Philip Yan \\ Working Paper 21166 \\ http://www.nber.org/papers/w21166
NATIONAL BUREAU OF ECONOMIC RESEARCH
1050 Massachusetts Avenue
Cambridge, MA 02138
May 2015

We thank Jeremy Stein, Charles Lee and seminar participants at Hong Kong University of Science and Technology, Baruch College, and Princeton University for helpful comments. The views expressed herein are those of the authors and do not necessarily reflect the views of the National Bureau of Economic Research.

NBER working papers are circulated for discussion and comment purposes. They have not been peerreviewed or been subject to the review by the NBER Board of Directors that accompanies official NBER publications.

(C) 2015 by Harrison Hong, Weikai Li, Sophie X. Ni, Jose A. Scheinkman, and Philip Yan. All rights reserved. Short sections of text, not to exceed two paragraphs, may be quoted without explicit permission provided that full credit, including (C) notice, is given to the source. 
Days to Cover and Stock Returns

Harrison Hong, Weikai Li, Sophie X. Ni, Jose A. Scheinkman, and Philip Yan

NBER Working Paper No. 21166

May 2015

JEL No. G12

\section{ABSTRACT}

The short ratio - shares shorted to shares outstanding - is an oft-used measure of arbitrageurs' opinion about a stock's over-valuation. We show that days-to-cover (DTC), which divides a stock's short ratio by its average daily share turnover, is a more theoretically well-motivated measure because trading costs vary across stocks. Since turnover falls with trading costs, DTC is approximately the marginal cost of the shorts. At the arbitrageurs' optimum it equals the marginal benefit, which is their opinion about over-valuation. DTC is a better predictor of poor stock returns than short ratio. A long-short strategy using DTC generates a $1.2 \%$ monthly return.

\author{
Harrison Hong \\ Department of Economics \\ Princeton University \\ 26 Prospect Avenue \\ Princeton, NJ 08540 \\ and NBER \\ hhong@princeton.edu
}

Weikai Li

Department of Finance

Hong Kong University of Science and Technology

Clear Water Bay, Kowloon, Hong Kong

wliaj@ust.hk

Sophie X. Ni

Department of Finance

Hong Kong University of Science

and Technology

Clear Water Bay, Kowloon, Hong Kong

sophieni@ust.hk
Jose A. Scheinkman

Department of Economics

Columbia University

New York, NY 10027

and NBER

js3317@columbia.edu

Philip Yan

Goldman Sachs Asset Management

200 West Street

New York, NY 10282

Philip.Yan@gs.com 


\section{Introduction}

A large literature going back to the early eighties examines the relationship between the short interest ratio of a stock (SR), defined as the shares shorted to the shares outstanding, and its expected return (see, e.g., Figlewski (1981), Brent, Morse, and Stice (1990), Figlewski and Webb (1993), Woolridge and Dickinson (1994), Dechow, Hutton, Meulbroek, and Sloan (2001), Asquith, Pathak, and Ritter (2005)). Papers typically find that stocks with a high SR significantly underperform stocks with a low one. The most natural interpretation of this finding is that since only professional investors short, this ratio is a signal of the pessimistic view of informed arbitrageurs trading against the over-pricing created by naive and optimistic retail buyers. ${ }^{1}$ But arbitrageurs are risk-averse or face capital constraints as in De Long, Shleifer, Summers, and Waldmann (1990) or Shleifer and Vishny (1997), and so do not short enough to eliminate the mis-pricing. ${ }^{2}$ As a result, short interest is associated with low expected return.

We show that SR, however, is not the theoretically correct measure of arbitrageurs' opinion about a stock's over-pricing when trading costs, such as brokerage house commissions or price impact, vary across stocks. A large literature in fact points to substantial crosssectional variation in trading costs (Amihud (2002), Amihud, Mendelson, and Pedersen (2006)). In such a setting, we prove that days-to-cover (DTC), which divides short ratio by average daily share turnover, is actually a more theoretically well-motivated measure. The reason is that DTC is approximately the marginal cost of the arbitrageur's short position.

Consider as an example two stocks A and B. Stock A with a short ratio of $5 \%$ and average daily turnover of $1 \%$ has a DTC of 5 days. Stock B with a short ratio of $5 \%$ and average daily turnover of $5 \%$ has a DTC of 1 day. The short on A has a higher marginal cost than the short on B and should then be perceived as more over-priced by the arbitrageurs to leave

\footnotetext{
${ }^{1} \mathrm{~A}$ more recent strand of the literature looks at the higher frequency trading strategies of shorts to support the view that short-sellers are indeed sophisticated arbitrageurs (see, e.g., Boehmer, Jones, and Zhang (2008), Diether, Lee, and Werner (2009), Engelberg, Reed, and Ringgenberg (2012)).

${ }^{2}$ See for instance Chen, Hong, and Stein (2002) which features risk-averse arbitrageurs who short but not sufficiently to offset the over-pricing of a stock. This interpretation has not been the one used to motivate why there is excessive predictability connnected with the short ratio. Rather, the literature has predominantly referred to short-sales constraints related to borrowing stock. But this interpretation is problematic since lending fee, and not short interest, is the right metric for over-valuation in this setting. So stocks with no short interest might simply be not easily borrowed.
} 
them indifferent at the optimum of their maximization program.

DTC is a widely monitored metric among short-sellers in practice. Short-sellers report that they prefer stocks where they are able to close or cover their positions quickly without having to account for a big part of the daily market volume. DTC is a measure of the ease with which they can achieve this goal. ${ }^{3}$ Yet, as far as we know, it has not been previously studied.

Consider then the first-order condition of a risk-neutral arbitrageur's maximization program when facing quadratic trading costs and where for simplicity there is no lending fee to establishing a short position and shares outstanding is normalized to one. The trading cost naturally constrains the size of the short position. The marginal cost of this position $\theta$ (in absolute value) is just $c \theta$, where $c$ is the exogenous per-share trading cost parameter. The marginal cost of the position equals the marginal benefit of the position, which is simply the over-pricing of the stock from the point of view of the arbitrageurs. Since $c$ is inversely related to the share turnover of a stock, as we show in a model below, the marginal cost of the position is simply DTC.

Put another way, arbitrageurs all else equal prefer to short a liquid name where it is easier to cover their positions. So stocks with high short interest may simply be easier to trade and not necessarily be extremely over-priced. When a stock's DTC is high, arbitrageurs are sticking their necks out by bearing a high marginal cost and hence we can infer that they are convinced of that stock being over-priced. As we will demonstrate below, this insight assumes that we hold fix any lending fee for shorting.

Indeed, the literature on shorting thus far has been largely concerned about the cost of borrowing shares or rolling over the shorts in the stock lending market as the key friction (see, e.g., D'avolio (2002), Geczy, Musto, and Reed (2002), Duffie, Garleanu, and Pedersen (2002), Jones and Lamont (2002), Ofek, Richardson, and Whitelaw (2004), Cohen, Diether, and Malloy (2007), Saffi and Sigurdsson (2010), Beneish, Lee, and Nichols (2013), and Drechsler and Song (2014)). Stocks with high lending fees for shorts are shown to under-

\footnotetext{
${ }^{3}$ We can equivalently, as practitioners do, calculate DTC using shares shorted to average shares traded daily; but for our empirical analysis below, it is more convenient to scale everything first by shares outstanding. The two ways of calculating are identical (absent significant changes in shares outstanding within a given month) and yield identical results.
} 
perform other stocks. We show that trading costs, holding fixed the stock-lending market friction, is also a first-order issue.

We derive our main result in a simple model with two groups of risk-neutral investors: optimistic retail investors and arbitrageurs whose expectations are tied to fundamental value. Both groups of investors face the same quadratic trading cost. A fraction of the optimists receive a preference or liquidity shock which generates share turnover. The lower is the cost of trading, the higher is share turnover as it is cheaper for them to adjust their positions. Arbitrageurs who want to short face the usual short-selling cost for borrowing the stock but also the trading cost since they need to sell and buy back their shares to cover their shorts.

We show that our main insight holds where turnover and prices are derived endogenously. Since the share turnover of a stock is also driven by liquidity trading among optimists and hence falls with trading costs, we can then use it to proxy for the trading frictions and prove that DTC captures the marginal cost (and hence the marginal benefit) of the short position. Our model's main prediction is that DTC ought to be a better measure of a stock's over-valuation and hence a better predictor of low expected stock return than SR.

Our sample period runs from 1988 to 2012. Our baseline DTC measure divides the short-interest ratio measured in a given month by the average daily turnover during the same month. ${ }^{4}$ In our sample, the mean DTC for a cross-section of stocks is 5.5 with a standard deviation of 8 days. In the time series, DTC has risen from a low of 3 days to 7 days during the recent sample. Importantly, we show that short ratio is strongly correlated with a stock's share turnover in the cross-section, consistent with our model. The correlation is .4 in the mid-point of our sample. Early in our sample period, the correlation of SR and turnover is .3. The correlation in the post-2000 sample is $.5 .^{5}$ We show that this correlation is not driven by the usual common factors such as firm size, book-to-market, past 12 months cumulative returns and institutional ownership or other well-known stock characteristics. This partial correlation is also .4 at the mid-point of our sample and exhibits similar time

\footnotetext{
${ }^{4}$ Our results are similar when we scale by average daily turnover calculated using data from prior months instead since liquidity tends to be persistent.

${ }^{5}$ While it is difficult to interpret time trends, it is comforting to know that the hedge fund sector and the amount of shorting rises in the market after the year 2000 (Hanson and Sunderam (2014)). In other words, we get this high correlation over a sample period when the arbitrageurs we envision in our model are active.
} 
trends as the raw correlation. These correlation patterns are consistent with, though not causal evidence of, the premise of our paper that short-sellers, all else equal, prefer to short more liquid stocks.

The key distinctive prediction of our model is really to compare the forecasting power of DTC with SR. We first verify the result in the literature that this month's SR negatively forecasts next month's stock return. An equal-weighted portfolio long the lowest SR decile and short the highest SR decile earns $.71 \%$ per month with a t-statistic of 2.57 . In contrast, we find that a strategy long low DTC decile stocks and short high DTC decile stocks yields $1.19 \%$ per month with a t-statistic of 6.67 . And also consistent with the literature, a value-weighted portfolio based on SR yields a statistically insignificant .29\% per month. In contrast, we find that a value-weighted DTC strategy yields a statistically significant $.67 \%$ per month. We also use the Sharpe ratio as a different metric to show that DTC is a more accurate gauge of over-pricing than SR. The Sharpe ratio for the SR long-short strategy is .5 over our sample. The Sharpe ratio for the long-short DTC strategy is 1.3.

Since the superiority of DTC over SR is premised on there being cross-sectional variation in trading costs, we expect that the difference between DTC and SR is lower when valueweighting returns or when we consider just big stocks. The reason is that there is less variation in trading costs among big stocks than small stocks. The differences between the DTC and SR strategies in these two instances are indeed smaller than in our baseline setting (equal-weighting returns and using all stocks) but nonetheless economically different at around .29\% per month. The same results hold when we use lagged share turnover create DTC since share turnover is a persistent variable.

This excess return predictability, in our model, reflects two forces. The first is the usual limits of arbitrage assumption that there is limited capital in short-selling. The second, and new to our model, is the trading costs and the associated risks of having to cover shorts on stocks that are difficult to buy back. Consistent with this effect, during the Short-selling Ban of US financial stocks in 2008, we find that shorting high DTC stocks indeed experienced significant losses compared to other stocks as short-sellers were forced to cover their shorts. The SR strategy experienced no such draw down. More generally, forced covering of shorts 
can come at the wrong time or be destabilizing and such effects are exacerbated for high DTC stocks (Hong, Kubik, and Fishman (2012), Lou and Polk (2013)). These costs might not be well captured by Sharpe ratios.

This difference in performance between DTC and SR is statistically significant across a variety of return benchmarks, such as Daniel, Grinblatt, Titman, and Wermers (1997) adjusted returns and the Carhart (1997) four-factor and Carhart (1997) plus Pastor and Stambaugh (2003) five-factor alphas. In other words, DTC's predictive power is not simply picking up a liquidity effect, which one might worry is the case since DTC scales SR by daily turnover. The reason of course, as we show in our model, is that since SR and turnover are correlated to begin with, adjusting for turnover isolates the overpricing effect. We then run a horse race between DTC and SR in a multiple regression. We find that DTC largely takes out the forecasting power of SR. In the post-2000 sample, SR is a very weak and statistically insignificant predictor, whereas DTC remains statistically significant.

Our model also generates the usual prediction that stocks with higher lending fees are more overpriced. But the lending fee effect is distinct from our DTC effect. Over a short sample since 2003, we also have lending fees by stock, which has also been shown to be a proxy for over-pricing. We find that DTC is as powerful a predictor as lending fees. Our lending fee data covers only the recent period. Following the literature, we adjust short interest by institutional ownership, SIO, to be a measure of lending fees. The motivation for SIO is to capture the extent of borrowing costs in the stock lending market by taking the ratio of demand for shorts to a proxy for the supply of shorts in the form of institutional ownership (Asquith, Pathak, and Ritter (2005), Nagel (2005), Drechsler and Song (2014)). Our effects are again robust to controlling for the SIO proxy of lending fees.

Finally, we also consider a series of robustness checks. First, we show that DTC is robust to how we construct it. Our baseline DTC variable divides SR by contemporaneous daily turnover averaged over the current month. But our results are robust to dividing by daily turnover averaged over previous months, going back over the past year.

Second, we show that our DTC variable is not mechanically related to other turnover based measures such as illiquidity (Amihud (2002)), which divides the absolute value of re- 
turns by share turnover. These two variables, though both have turnover in the denominator, are not strongly correlated. The same is true if we use the inverse of turnover. The reason is that SR is strongly correlated with turnover. We show that the forecasting power of DTC is not related to the forecasting power of illiquidity or other turnover measures (Gervais, Kaniel, and Mingelgrin (2001)).

We are not the first paper to observe that SR is a theoretically problematic measure of overpricing due to costly short-selling when arbitrage or trading costs vary across stocks. Chen, Hong, and Stein (2002) developed a breadth of ownership measure, which they argued was unambiguously correlated with over-pricing, driven by such a motivation. We show that adjusting SR by the cost of trading naturally deals with such cost heterogeneity in the cross-section.

Our paper is related to an emerging literature on the importance of shorting restrictions for asset price bubbles and crashes (Miller (1977), Harrison and Kreps (1978), Scheinkman and Xiong (2003), Hong, Scheinkman, and Xiong (2006), Hong and Stein (2003)). It is also related to a burgeoning literature on the importance of short-selling costs in accounting for why many return predictability patterns are stronger on the short-leg (see, e.g., Hong, Lim, and Stein (2000), Stambaugh, Yu, and Yuan (2012), Hirshleifer, Teoh, and Yu (2011)).

Our paper proceeds as follows. Section 2 outlines our model and develops our hypothesis. Section 3 describes the various data we used in the analysis. Section 4 presents our empirical results, and Section 5 concludes.

\section{Model}

We develop a model to demonstrate the problematic nature of SR as a measure of arbitrageur opinion regarding stock over-pricing and why DTC is a more robust one when there are trading costs that vary across stocks. There are three dates $t=0,1,2$. The asset yields a payoff at $t=2$. There are two types of agents. A fraction $\gamma$ of the agents are arbitrageurs and a fraction $1-\gamma$ of the agents are optimists. Optimists believe that the random payoff has a mean $\mu_{o}$. They start with one unit of the asset per-capita. Arbitrageurs have no endowment but believe that the payoff has mean $\mu_{a}<\mu_{o}$. All agents are risk-neutral and 
they face the same trading and shorting costs.

Before trading at $t=1$, half the optimists learn that they will value each dollar at $t=2$ as $1<\delta<2$ dollars. The other half at the same time learn that they will value each dollar at $t=2$ as $\delta^{\prime}=2-\delta$ dollars. In equilibrium, the optimists that receive the positive time preference shock $\delta$, more preference for the future, buy shares, whereas the ones that receive a negative time preference shock $2-\delta$, less preference for the future, would like to sell shares.

As such, there are two sources of trading in our model. The first is the differences in beliefs between the optimists and the arbitrageurs. The other is liquidity needs among the optimists which we generate using this preference shock. Even though turnover in our model reflects both trading motives, we show nonetheless that adjusting short interest by turnover is the appropriate way to capture the marginal cost of short-selling for arbitrageurs.

To solve our model, we start with the portfolio maximization problem of the optimists. Optimists that receive the positive preference shock $\delta$ will choose a net demand $n_{o}^{+}$at $t=1$ that solves:

$$
\max _{n}\left\{(1+n) \delta \mu_{o}-n p_{0}-\frac{c}{2} n^{2}\right\}
$$

where $p_{0}$ is the price at $t=0$ and $c$ is the quadratic trading cost parameter. Notice that $n$ denotes the net demand and $(1+n)$ is the investor's endowments of the shares plus his position. Thus the net demand by optimists that receive the positive time preference shock is:

$$
n_{o}^{+}=\frac{\delta \mu_{o}-p_{0}}{c}
$$

Optimists that receive the negative preference shock $2-\delta$ face a similar maximization problem and will choose a net demand $n_{o}^{-}$that solves:

$$
\max _{n}\left\{(1+n)(2-\delta) \mu_{o}-n p_{0}-\frac{c}{2} n^{2}\right\}
$$

It follows then that the net demand by optimists that receive the negative time preference shock is:

$$
n_{o}^{-}=\frac{(2-\delta) \mu_{o}-p_{0}}{c}
$$


The demand by arbitrageurs at $t=1$ can be obtained by solving the following:

$$
\max _{n}\left\{n\left(\mu_{a}+f-p_{0}\right)-\frac{c}{2} n^{2}\right\}
$$

where $f$ is the fee to shorting. We assume that the lending fee is exogenous to start and that the fee is collected by a broker. In the Appendix, we endogenize the lending fee and show that the main conclusions remain. If the arbitrageurs short, $n<0$, then $n f$ is the total short-fees paid by the arbitrageurs. Recall that they have no initial endowment to begin with. Their demand is then given by

$$
n_{a}=\frac{\mu_{a}+f-p_{0}}{c}
$$

Remark 1: Following the literature on trading costs (see, e.g., Vayanos (1998)), we think of the quadratic trading cost function as a reduced form for brokerage commissions, transaction taxes and price impact, which are important in many markets and vary across stocks. Under a price impact interpretation, quadratic trading costs in our model, $\frac{1}{2} c n^{2}$, can be thought of in a couple of ways. One way is with idiosyncratic liquidity shocks which force the investors to independently and prematurely close their positions. With probability $\frac{1}{2}$, the short-seller receives a liquidity shock and has to close his short position and buy back the shares. Since the optimists still want to hold onto their shares, this will lead to price impact. Market makers can then provide liquidity in this situation. The cost of a position $n$ means the investors have to trade away from the average price by an amount $c n$. Here $c$ can then be interpreted as inventory considerations in Grossman and Miller (1988). The total expected cost of trading then at $t=0$ is $\frac{1}{2} n(c n)$ or $\frac{1}{2} c n^{2}$. With probability $\frac{1}{2}$, short-sellers do not receive an unexpected liquidity shock which forces them their close position prematurely. A similar argument applies for the optimists.

We will focus on the equilibrium in which the optimists that receive a negative preference shock sell some of their shares and the arbitrageurs short. To this end, we require the 
following set of parameter restrictions:

$$
\delta \mu_{o}>p_{0}>\max \left\{(2-\delta) \mu_{o} ; \mu_{a}+f\right\}
$$

and

$$
p_{0} \leq(2-\delta) \mu_{o}+c
$$

The first set of three parameter restrictions in Equation (7) essentially says that the optimists with the positive preference shock $\delta$ buy but the optimists with the negative preference shock sell while the arbitrageurs short-sell. The second parameter restriction in Equation (8) says that the optimists with the negative preference shock do not short-sell.

Remark 2: In addition, the analysis would be identical if each group $i \in\left\{o^{-}, o^{+}, a\right\}$ of traders was made up of $k_{i}$ homogeneous traders and the cost of transactions depended on the total amount traded by the group. In this case, an individual arbitrageur $\ell$ would take the trading of all other arbitrageurs as given and maximize:

$$
\max _{n_{\ell}}\left\{n_{\ell}\left(\mu_{a}+f-p_{0}\right)-\frac{c}{2}\left(n_{\ell}+\sum_{j \neq \ell} n_{j}\right)^{2}\right\},
$$

and, in an interior equilibrium,

$$
n_{\ell}+\sum_{j \neq \ell} n_{j}=\frac{\mu_{a}+f-p_{0}}{c}
$$

Thus equation (23) still holds, provided we interpret $n_{a}$ as the aggregate demand by arbitrageurs. A similar reasoning applies to equations (2) and (4).

Adding up the demand of the three types of agents at $t=1$ we get the market clearing condition in net demands:

$$
\gamma\left[\mu_{a}+f-p_{0}\right]+\frac{1-\gamma}{2}\left[(2-\delta) \mu_{0}-p_{0}\right]+\frac{1-\gamma}{2}\left[\delta \mu_{0}-p_{0}\right]=0
$$


which results in an equilibrium price of

$$
p_{0}=(1-\gamma) \mu_{o}+\gamma \mu_{a}+\gamma f=\mu_{a}+(1-\gamma)\left(\mu_{o}-\mu_{a}\right)+\gamma f
$$

We can think of the first term $\mu_{a}$ as the fundamental value associated with the expectation of the risk-neutral arbitrageurs. The second two terms, both of which are positive, reflect then the overpricing due to costly short-selling $\gamma f$ and costly trading $(1-\gamma)\left(\mu_{o}-\mu_{a}\right)$. Notice that the quadratic cost of trading $c$ does not appear in the pricing equation since it affects the positions of both the risk-neutral optimists and arbitrageurs symmetrically. The reason for this is that the optimists are initially endowed with all the supply of shares. So when the cost of trading $c$ goes up, there is both less shorting by arbitrageurs but also less trading on the part of the optimists. As a result, price is unaffected by the trading $\operatorname{cost} c$.

This then leads us to our first proposition.

Proposition 1. The degree of overpricing is given by

$$
p_{0}-\mu_{a}=(1-\gamma)\left(\mu_{o}-\mu_{a}\right)+\gamma f
$$

The short interest ratio (since total shares is normalized to $1-\gamma$ ) is given by

$$
S R=\frac{\gamma}{1-\gamma}\left|n_{a}\right|=\frac{\gamma}{1-\gamma} \frac{\left(p_{0}-f-\mu_{a}\right)}{c}=\frac{\gamma\left(\mu_{o}-\mu_{a}-f\right)}{c} .
$$

Proposition 1 points out the problematic nature of short interest as a measure of the degree of overpricing which centrally depends on $\mu_{o}-\mu_{a}$. Since the degree of overpricing is independent of $c$, while the short-interest is inversely related to $c$, it might simply be that high short-interest stocks are not more overpriced but simply easier to trade. The marginal cost of the short position is $c S R$, which by the first-order condition, equals the marginal benefit of the short position $\left(\gamma\left(\mu_{o}-\mu_{a}-f\right)\right)$ or the disagreement by the optimists and the arbitrageurs.

We next show that DTC, which divides short-interest by the number of shares traded, is a more robust measure of overpricing because it better approximates $c S R$. 
Proposition 2. Since only the optimists that receive the positive preference shock are buyers, share turnover is given by

$$
V=\frac{\frac{1-\gamma}{2} n_{o}^{+}}{1-\gamma}=\frac{1}{2} \frac{\delta \mu_{o}-p_{0}}{c}
$$

And

$$
D T C:=\frac{S R}{V}:=\frac{\gamma\left|n_{a}\right|}{(1-\gamma) V} \sim \frac{2}{(\delta-1) \mu_{o}} \gamma\left(\mu_{o}-\mu_{a}-f\right)
$$

is approximately the marginal cost of the short.

Proof.

$$
D T C=\frac{S R}{V}=\frac{\gamma\left(\mu_{o}-\mu_{a}-f\right)}{c} \frac{2 c}{\delta \mu_{o}-p_{0}}=2 \gamma \frac{\left(\mu_{o}-\mu_{a}-f\right)}{\delta \mu_{o}-\mu_{o}+\gamma\left(\mu_{o}-\mu_{a}-f\right)}
$$

Since $\gamma$ is small and using the Taylor expansion at $x=0$,

$$
\frac{x}{y+x} \sim 0+\frac{x}{y}=\frac{x}{y}
$$

for $x$ small, we write using $x=\gamma\left(\mu_{o}-\mu_{a}-f\right)$

$$
D T C \sim \frac{2}{(\delta-1) \mu_{o}} \gamma\left(\mu_{o}-\mu_{a}-f\right)
$$

Remark 3: Proposition 2 suggests that DTC may be a more robust measure of overpricing than $S R$. If $c$ varies in the cross-section, $S R$ will vary even for stocks with the same amount of overpricing. DTC on the other hand is independent of $c$. One possible problem with DTC is that $\mu_{o}$ appears in the denominator of the expression. This is less of a problem in regressions that depend on ranking stocks, since the ranking of $\mu_{o}-\mu_{a}$ is identical to the ranking of $\frac{\mu_{o}-\mu_{a}}{\mu_{o}} .{ }^{6}$. DTC will also perform better when $\mu_{o}$ does not vary a lot across stocks and most variations in expected returns come from $\mu_{a}$.

Another reason why both short-interest and DTC may be problematic is that they also depend on $f$. The higher is the fee, the higher is the overpricing but the lower are short-

\footnotetext{
${ }^{6}$ Since $\frac{f}{\mu_{o}}$ also appears in the expression for DTC, this also requires that the fee $f$ is small relative to the excess optimism $\mu_{o}-\mu_{a}$
} 
interest and DTC. In practice, the lending fee $f$ does not vary as much across stocks as c. Moreover, we can observe lending fee $f$ and include it in our empirical analysis. In the Appendix, we show that the main conclusions from Propositions 1 and 2 remain when we endogenize the lending fee as long as the parameter $\gamma$, the fraction of arbitrageurs, is small relative to the population.

\section{Data, Variables and Summary Statistics}

We obtain monthly short interest data from the NYSE, Amex and Nasdaq exchanges from 1988 to 2008. The exception is for Amex from 2005-2008, which are from Compustat. Short interest data from 2009 to 2012 are obtained from Compustat. ${ }^{7}$ We use the short interest data that is reported in a given month, typically the mid-point. We start our sample in 1988 since there is little shorting earlier than this date. To form short interest ratio (SR), we normalize short interest by total shares outstanding from CRSP.

In addition to data on the level of short interest, we also construct two variables proxy for stocks' loan fees from the Markit equity lending database. The first variable, Fee1, is the simple average fees of stock borrowing transactions from hedge funds in a given security, which is the difference between the risk-free rate and the rebate rate. Fee1 is only available for a stock to the extent that the stock is being shorted by a hedge fund. The second variable, Fee2, which covers all stocks, is a score from 1 to 10 created by Markit using their proprietary information meant to capture the cost of borrowing the stock. Here 1 is the cheapest to short and 10 the most difficult. The first fee variable is available since November of 2006 while the second fee variable is available since October of 2003 .

Data on monthly stock returns and daily trading volume are obtained from CRSP. We require stocks to be listed on NYSE, AMEX and NASDAQ and common stocks (i.e. share type code equals to 10 or 11). Turnover is calculated as the daily ratio of the number of total shares traded to the number of total shares outstanding. The daily turnover ratio is averaged within a month to get a monthly variable. Since the dealer nature of the NASDAQ market

\footnotetext{
${ }^{7}$ The NYSE-AMEX data is available on Compustat starting in 1976. The NASDAQ data is only available starting in 2003. There are two versions: unadjusted and adjusted for stock splits. The exchange data we are using is unadjusted.
} 
makes the turnover on it difficult to compare with the turnover observed on NYSE and AMEX, we follow Gao and Ritter (2010) by adjusting trading volume for NASDAQ stocks. ${ }^{8}$ We use standard control variables in our empirical analysis part. Size (LnME) is defined as natural logarithm of market capitalization at the end of June in each year. Book value equals the value of common stockholders' equity, plus deferred taxes and investment tax credit, minus the book value of preferred stock. Book-to-market (LnBM) ratio equals to the most recent fiscal year-end report of book value divided by market capitalization at the end of calendar year t-1. Momentum (Mom) is defined as the cumulative holding-period return from month t-12 and t-2. We follow the literature by skipping the most recent month return when constructing Momentum variable. The short term reversal measure (REV) is the prior month's return. Institutional ownership (IO) is the sum of shares held by institutions from $13 \mathrm{~F}$ filings in each quarter divided by total shares outstanding. Firm-level variables are obtained from Compustat annual files. Data on institutional holdings is from Thompson Reuters Financial.

In empirical analysis section, we compute monthly characteristic adjusted return by subtracting the stock's raw return by the return of the benchmark group to which the stock belongs to (see, e.g., Daniel, Grinblatt, Titman, and Wermers (1997)). The $5 * 5 * 5$ benchmark groups are formed at the end of June of each year based on size, book-to-market ratio, and past one year return. The monthly benchmark returns and stock assignments are obtained from Russ Wermer's website.

\subsection{Correlation between Short Ratio and Turnover}

We start by examining the cross-sectional correlation between short ratio (SR) and our main proxy for trading cost: share turnover. Panel A of Figure 1 depicts the cross-sectional correlation between SR and turnover across time. That is, for every month, we calculate the cross-sectional correlation between SR and turnover. We then plot these cross-sectional correlations over time. Note that the correlation between SR and turnover is positive and

\footnotetext{
${ }^{8}$ Specifically, we divide NASDAQ volume by $2.0,1.8,1.6$, and 1 for the periods prior to February 2001, between February 2001 and December 2001, between January 2002 and December 2003, and January 2004 and later years, respectively.
} 
has increased over time. In the beginning of our sample in 1988, the correlation is around 0.3 to 0.4 . But since the $2000 \mathrm{~s}$, this correlation is around 0.5 to 0.6 . These results are using contemporaneous values of short ratio and turnover but the same thing holds if we used lagged values of turnover.

We next show that these correlations are not driven by omitted valuation factors. To control for other factors that can potentially confound the cross sectional correlations, we compute the partial correlation between short ratio and share turnover controlling for size, book-to-market, past 12 months cumulative returns and institutional ownership. Specifically, every month $t$ we run the regressions

$$
\begin{gathered}
S R_{i t}=\alpha_{t}^{S R}+\beta_{i t}^{S R} X_{i t}+u_{i t}^{S R} \\
T_{i t}=\alpha_{t}^{T}+\beta_{i t}^{T} X_{i t}+u_{i t}^{T}
\end{gathered}
$$

where $X_{i t}$ is our collection of control variables, and $T_{i t}$ is our trading cost proxy share turnover. The cross-sectional partial correlation between short ratio and turnover in time $t$ is given by

$$
\rho_{t}=\operatorname{Corr}\left(\hat{u}_{i t}^{S R}, \hat{u}_{i t}^{T}\right)
$$

Panel B of Figure 1 plots the partial correlation of SR with turnover. We see that the observations made in the univariate correlation case earlier remain true after controlling for other variables. The overall magnitude of the correlation is smaller, dropping in the post2000 sample from around .5 to .6 around .4 to .5. The partial correlations are nonetheless still positive. Moreover, we see a similar pattern overtime with the correlation becoming stronger in the recent period. These findings are consistent with our model where a common trading cost parameter influences both share turnover and short interest.

\subsection{Days-to-Cover: Scale Short Ratio by Share Turnover}

Based on the analysis in our hypothesis development section, we consider Days-to-cover (DTC) measure, which scales SR by share turnover, as a superior measure of arbitrageur 
opinion about a stock's over-pricing. Specifically, DTC is defined as

$$
D T C=\frac{S R}{\text { AverageDailyTurnover }}
$$

Recall SR is typically measured at the middle of a given month. The average of daily turnover is taken with respect to the same month's daily share turnover. ${ }^{9}$ Below, we consider averaging turnover over prior months and find similar results. The DTC measure has an intuitive interpretation as roughly how many days of average share volume it would take for all short sellers to cover their short positions. Figure 2 plots the market average short ratio, turnover and DTC measure in time series. There is an increasing trend for both SR and turnover. Short ratio is negligible in the beginning of our sample period, at around 1\%, and then steadily rises and peaks in 2008 at around 5.5\%. It has subsequently fallen back to around $4 \%$ in the most recent years of our sample.

Share turnover also improved dramatically during this period, as indicated by the upward trend of market mean turnover ratio. To put daily turnover on the same scale, we multiplied by 1000 . In 2008, mean daily turnover is 8 in units of 1000 , which translates into $0.8 \%$ per day or roughly $200 \%$ per year. In the beginning of the sample, the daily turnover is a fraction of this, at around .20\% per day or $50 \%$ per year.

However, SR increases more than turnover ratio, so mean days-to-cover (DTC) also increased a lot, from around 3 day to about 7 days. The rise of SR due to hedge fund or arbitrageur activity is well known. One can interpret that the latter part of our sample might be especially relevant in terms of evaluating our model since this is when there are significant levels of short-selling or arbitrageur activity.

\subsection{Summary Statistics}

To dig deeper into these numbers, Table 1 presents the summary statistics for the variables used in our analysis. Panel A reports the mean and standard deviation of the variables for the full sample and by market capitalization quintiles. We start with SR. It has a mean

\footnotetext{
${ }^{9}$ We can also calculate DTC using shares shorted to average shares traded daily but for exposition it is more convenient to scale everything first by shares outstanding.
} 
of 2.26\%. Note that there is more shorting in Size Quintiles 2-4 than in Quintiles 1 and 5, consistent with Hanson and Sunderam (2014). The mean turnover in our sample is .46\% per day. The mean DTC in our sample is 5.45 days with a standard deviation of 8.26. Notice that the standard deviation of DTC is quite large and this will play a key role in our analysis below. The mean institutional ownership in our sample is $42 \%$. The remaining summary statistics are well known and do not require additional discussion.

Panel B of Table 1 reports these statistics for our sub-sample where we also have lending fee data. More specifically, we use the sub-sample where Fee2 is available which is starting from October 2003. Fee2 is Markit's internal rating system for whether a stock is difficult to borrow for shorting, where 1 is cheapest and 10 is the most difficult. We also report summary statistics for Fee1 which is the simple average of fees of the stock borrowing transactions among hedge funds, which is available only in more recent sample starting in November 2006.

Notice that both SR and DTC have higher means, $4.32 \%$ and 6.85 respectively, in this sub-sample since it is more recent. A similar comment holds for institutional ownership, which is $58.71 \%$ in this sample. Importantly, notice that Fee2 has a mean of 1.39 and a standard deviation of 3.56. In other words, stocks are very easy to short in that the lending fees are not that high. Importantly, notice that this number is fairly consistent across Size Quintiles. If we look at Fee1, we see that the mean is 48 basis points with a standard deviation of 91 basis points. In most instances, the fees are small and we can treat that as largely fixed and exogenous for our purposes.

To take this point a bit further, Panel $\mathrm{C}$ of Table 1 reports the pairwise correlations among our variables where they overlap. The correlation between DTC and SR is high at .83 but far from perfectly correlated, as what be predicted by our model since trading costs vary across stocks (i.e. turnover varies) and shorts are influenced by the same underlying unobservable costs (i.e. SR covaries with turnover as we have already established). Indeed, there is different information captured in these two variables which we will exploit in our asset pricing exercises below.

The other notable correlation is that DTC is not very correlated with IO, Fee1 and Fee2. 
They are $.3, .17$ and .04 , respectively. This points to the fact that the issue we are dealing with regarding the influence of heterogeneous trading costs on shorting is an independent issue from the lending market frictions that have been emphasized in the literature.

\section{Empirical Results}

Our main hypothesis is that the Days-to-Cover (DTC) is a superior measure of arbitrageurs' opinion about over-pricing, as it captures the marginal costs of shorts as opposed to SR in a world where trading costs vary across stocks. Consequently, we predict that DTC should more strongly and negatively predict subsequent stock returns than short ratio. In this section, we test this hypothesis using both portfolio sorts and multiple regressions.

\subsection{Portfolio Sorts Using DTC and SR}

In this section, we show that stocks sorted on DTC generate larger and more significant return spreads than stocks sorted on SR. We conduct the decile sort test as follows. At the end of each month, we sort stocks into deciles based on either SR or DTC. We then compute the average return of each decile portfolio over the next month, both value-weighted and equal-weighted. This gives us a time series of monthly returns for each decile. We use these time series to compute the average return of each decile over the entire sample. As we are most interested in the return spread between the two extreme portfolios, we only report the return to a long-short portfolio, i.e., a zero investment portfolio that goes long the stocks in the lowest SR/DTC decile and shorts the stocks in the highest SR/DTC decile. ${ }^{10}$ We report the average return (and associated t-statistics) of this long-short portfolio in the left columns, the characteristics-adjusted return spread, computed in the way described by Daniel, Grinblatt, Titman, and Wermers (1997) and denoted DGTW in the middle columns and the 5-factor adjusted alpha (the return adjusted by the Fama-French three factors, the momentum factor, and the Pastor and Stambaugh (2003) liquidity risk factor) in the right columns.

\footnotetext{
${ }^{10}$ The mean DTC for the decile 1 portfolio is 0.126 , while the mean DTC is 25 for the decile 10 portfolio.
} 
In Table 2, we start by replicating the findings for SR. Panel A reports the results for equal-weighted portfolios and Panel B reports for value-weighted portfolios. Our analysis uses the full sample period, starting in January 1988 and ending in December 2012. The average equal-weighted return difference between the lowest SR decile portfolio and highest SR decile portfolio is a monthly $.71 \%$, with a t-stat of 2.57 . The Sharpe ratio is .51. A DGTW adjustment leads to a lower return of $.49 \%$ and a lower Sharpe ratio of .39. Four-factor and five-factor alphas are around $1 \%$ with a t-statistic of 6 . Panel B reports the value-weighted results. They are, consistent with the literature, smaller than the equal-weighted results. Indeed, for the excess return and DGTW return, they are statistically insignificant; for the four-factor and five-factor alphas, they are around $.45 \%$ with a t-statistic of around 2 .

In Table 3, we report the analogous results using DTC instead of SR. In Panel A, the equal-weighted return to the long-short portfolio sorted on DTC is a monthly $1.19 \%$ per month, with a t-stat of 6.67 . The Sharpe ratio is 1.33 . These figures are significantly larger than those for SR. For DGTW returns, the numbers are very similar. The four-factor and five-factor alphas are $1.3 \%$ per month with t-statistics of around 8. In Panel B, we see that the value-weighted results are weaker but are nonetheless statistically and economically significant across the board. For excess returns, it is $.67 \%$ with a t-statistic of 2.24 . For DGTW returns, it is $.59 \%$ with a t-statistic of 2.56 . The figures are around $.70 \%$ for the four- and five-factor alphas and both figures are also statistically significant. So regardless of the metric, DTC outperforms SR in these portfolio sorts.

In Table 4, we formally test the difference between DTC and SR across a variety of samples. As a baseline, we report the full sample results. The difference in the equal-weighted portfolio strategies is $.46 \%$ and statistically significant at 2.65 . Since the superiority of DTC over SR is premised on there being cross-sectional variation in trading costs, we expect and find that the difference between DTC and SR is lower when value-weighting returns. The reason is that there is less variation in trading costs among big stocks than small stocks. For value-weighted portfolios, the difference is $.36 \%$, which is economically significant, but the t-statistic is 1.18. In the remaining sub-samples, we use equal-weighted portfolios.

We next check whether our results hold not only in the full sample, but also in each of 
two sub-periods: one that starts in January 1988 and ends in December 1999, and another that starts in January 2000 and ends in December 2012. We choose 2000 as the breakpoint as hedge fund activity is more significant after 2000. Notice that DTC outperforms SR by $.37 \%$ in the first half of the sample and by $.53 \%$ in the second half of the sample. So the out-performance is consistent across both sub-samples.

The third row of Table 4 shows that our results hold for stocks listed on both NYSE-Amex and NASDAQ stock exchanges. This assures us that our results are robust with respect to the different ways trading volume is counted for NYSE-Amex and NASDAQ listed stocks. DTC does better than SR in the NYSE-Amex sample by .41\%. And it also out-performs SR in the Nasdaq sample by $.62 \%$.

The fourth row shows that sorting stocks into either 5 portfolios or 20 portfolios does not change our results. Using 5 portfolios, the outperformance of DTC compared to SR is $.36 \%$. Using 20 portfolios, the outperformance is $.59 \%$.

In Figure 3, we take a more detailed look and report by decile portfolios the equalweighted DGTW adjusted portfolio returns for SR and DTC. One can see that DTC outperforms SR across every decile except for deciles 4-6. In deciles 1-3, the low DTC outperforms low SR in terms generating higher returns. In deciles 7-10, high DTC outperforms high SR in terms of generating lower returns. Take the decile 10 high DTC and decile 10 high SR portfolios. For the high SR, the return is around -.30\%. For DTC, it is $-.40 \%$. One can also see that the pattern for DTC is fairly monotonic, consistent with our model. The lowest DTC decile portfolio has a return of nearly .50\%. So the spread across 10 to 1 is almost $1 \%$ and monotonic across deciles. This is not the case for SR as the performance of lower SR decile 1-2 portfolios have actually lower returns than their higher decile counterparts. Any model of limits of arbitrage limiting the degree of short-selling predicts that the relationship between SR and over-pricing should be monotonic.

The fifth row shows the results when we remove micro-cap stocks. First we remove stock in the bottom $10 \%$ of market capitalization using the NYSE cutoff. SR has a $.55 \%$ monthly return compared to an $.84 \%$ monthly return of DTC. The monthly difference of $.29 \%$ is significant with a t-statistic of 1.76 . When we drop the bottom $20 \%$, the return difference 
is $.25 \%$ per month. In other words, DTC is more valuable when considering all stocks than when considering just large stocks. The reason is that dropping the smaller stocks reduces variation in trading costs in our sample, which means adjusting for trading costs becomes less valuable. Nonetheless, we still see even among fairly large stocks in the universe that we have meaningful differences in performance between DTC and SR.

The sixth row of the Table 4 shows that we obtain similar results if we exclude stocks whose price at the sorting month is below $\$ 5$. Again, DTC outperforms SR to the tune of $.36 \%$ per month. Across almost all the specifications in Table 4, DTC economically and statistically outperforms SR.

To get a better sense of how the DTC strategy compares with the SR strategy from an investor's perspective, we compute the cumulative returns to SR and DTC spread portfolio. Figure 4(a) shows that DTC strategy outperforms SR strategy dramatically for the equalweighted return, especially after 2000. One dollar invested in the long-short portfolio sorted on DTC at the beginning of 1988 will grow to 30 dollars at the end of our sample period, while this number is 6 dollars if investing based on the SR strategy. The cumulative returns of DTC uniformly beat the returns of SR in almost all of our sample period. We have to be careful in interpreting these graphs since they are dependent on how the strategies did initially. The mean monthly differences are more robust to when one starts the sample.

Figure 4(b) reports the cumulative returns for value-weighted portfolios. The DTC strategy also works better than the SR strategy even for value-weighted returns, although the magnitudes are less dramatic for the reasons outlined above. Interestingly, there is a significant draw-down in the strategy of DTC during the short-selling ban of 2008. The noticeable drawdown in the DTC strategy occurs mostly in the week of the ban from September 17 to October 8 of 2008. The ban meant that the short-sellers had to cover their short positions and high DTC stocks means it is harder to cover, resulting in greater losses. We view it as comforting that DTC is indeed capturing accurately the marginal cost of shorts, i.e. stocks that are more difficult to buy back. Without this drawdown, the value-weighted DTC strategy would out-perform SR by even more.

Figure 5 reports the trailing ten-year Sharpe ratios for SR and DTC over our sample 
period. Again, we see that the Sharpe ratio for DTC is much higher than SR over the whole sample period. The Sharpe ratio for DTC is almost always above 1 over our sample period. The SR is consistently around .5.

Figure 6 compares the annual equal-weighted returns to SR and DTC spread portfolio. This figure also highlights the lower volatility of returns to DTC strategy than SR strategy. As we can see, DTC strategy delivers positive annual returns in 23 out of 25 years, while returns to the SR strategy is positive in 17 years. DTC strategy outperforms SR strategy in 20 out of 25 years.

\subsection{Multiple Regressions with DTC and SR}

We now test our main hypothesis using the Fama-Macbeth regression methodology. One advantage of this methodology is that it allows us to examine the predictive power of SR and DTC while controlling for known predictors of cross-sectional stock returns. This is important because, as shown in Table 1, SR and DTC variables are correlated with some of these predictors. We conduct the Fama-Macbeth regressions in the usual way. Each month, starting in January 1988 and ending in December 2012, we run a cross-sectional regression of stock returns on SR and/or DTC and a set of control variables known to predict returns.

Table 5 reports the time-series averages of the coefficients on the independent variables. The three columns in the table correspond to three different regression specifications which differ in the number of control variables they include. The table provides further empirical support for our hypothesis. Column (1) and (2) shows that both SR and DTC strongly and negatively predict subsequent stock returns in the cross-section when entering into the regression alone, even after controlling for other known predictors of returns such as Market beta (Beta), market capitalization (LnME), book-to-market ratio (LnBM), short-term reversal (Rev) and past 1-year return (Mom). The statistical significance, however, is much higher for DTC $(\mathrm{t}=-9.55)$ than for $\mathrm{SR}(\mathrm{t}=-5.77)$.

In column (3), we run a horse race between SR and DTC by including both in the FamaMacbeth regression. The coefficient on SR is cut by half and is significant only at $10 \%$ level, while the coefficient on DTC is largely unchanged and remains highly significant. This is 
consistent with the results obtained from portfolio sorting that DTC is a stronger and more reliable negative predictor of cross-sectional stock returns than SR. To get a sense of the magnitude, the coefficient of -0.0431 on SR implies that a one-standard deviation spread in SR generates a differential in expected returns of $0.16 \%$. The coefficient of -0.0003 on DTC, however, implies that a one-standard deviation spread in DTC generates a differential in expected returns of $0.25 \%$, which is $50 \%$ higher than SR. ${ }^{11}$

In Panel B of Table 5, we show that DTC subsumes the power of SR in predicting future stock returns in the post-2000 sample. Here we run Fama-Macbeth regression separately for pre-2000 and post-2000 sample. As reported in column (1) and (4), when only SR is included in the regression, the coefficient on SR for the pre-2000 sample is two times that for the post-2000 sample. The coefficient on DTC, however, is the same in both samples. In column (3) and (6), we report the results when both SR and DTC are included in regression. In both sub-samples, DTC significantly reduces the coefficient on SR, both statistically and economically. However, SR is still marginally significant at $10 \%$ level for the pre-2000 sample, but completely loses its significance for the post-2000 sample.

\subsection{The Effect of DTC Controlling for Lending Fees}

In Table 6, we consider how our results change when we add in lending fees as a control. We have three measures of lending fees. The first is Fee1, which again is the average of the fee observed in hedge fund borrowing transactions. The results are in columns (1)-(3). In columns (4)-(6), we add Fee2, Markit's estimate of the lending fee, as a covariate. In columns (7)-(9), we take short interest scaled by institutional ownership, SIO, to be a measure of the lending fee. The motivation for SIO is to proxy for the size of the lending fee by taking the ratio of demand for shorts to a proxy for the supply of shorts in the form of institutional ownership (Asquith, Pathak, and Ritter (2005), Nagel (2005), Drechsler and Song (2014)).

In columns (1)-(3), we see that SR is insignificant in the Fee1 sample. Notice that Fee1 is a very short sample starting in November 2006. So the lack of statistical significance is not

\footnotetext{
${ }^{11}$ Note that our long-short DTC portfolios from the previous section make a much more extreme comparison than the one-standard deviation move considered here, thereby yielding more dramatic differences in portfolio returns (see Figure 3).
} 
surprising. Moreover, the coefficient on SR is -.03, which is still economically much smaller than before. But Fee1 is also not significant. DTC in this sample is still significant with a t-statistic of -1.71. In column (3), we find that DTC is a more significant predictor than SR. Indeed, in this specification, DTC attracts a coefficient of -.0003 and a t-statistic of -2.48 , which is fairly comparable to our results from Table 5 Panel B covering the post-2000 period. In other words, DTC is very robust to different sub-periods and controlling for Fee1.

In columns (4)-(6), we control for Fee2. In this larger sample, we see that the coefficient in $\mathrm{SR}$ is still small, at around -.0251 but now has a t-statistic of -1.56 . The coefficient on Fee2 is -.0027 with a t-statistic of -3.81 . This is consistent with the literature that lending fees are a significant predictor of poor returns consistent with binding short-sales constraints and over-pricing. In column (5), we see that DTC still attracts a coefficient of -.0003 with a t-statistic of -2.86 . The significance of Fee2 is similar to column (4). The economic and statistical significance of DTC is also comparable to Fee2.

In columns (7)-(9), our effects are again robust to controlling for lending fees. The coefficient on SIO is -.0186 with a t-statistic of -7.25 in the column (7). The coefficient on SR is insignificant. In column (8), the coefficient on DTC is -.0002 with a t-statistic of -4.05. The coefficient on SIO is -.0142 with a t-statistic of -5.34. So DTC is comparable in economic significance to SIO in this sample. A similar conclusion holds from column (9).

\subsection{Alternative Specifications and Ways of Calculating DTC}

In Table 7 , we use $\log ($ DTC $)$ rather than DTC and we draw similar conclusions. In column (1), the coefficient on $\log (\mathrm{SR})$ is -.0006 with a t-statistic of -2.74 . In column (2), the coefficient on $\log ($ DTC ) is -.0011 with a t-statistic of -5.54. When we run a horse race between $\log (\mathrm{SR})$ and $\log (\mathrm{DTC})$, the coefficient on $\log (\mathrm{SR})$ is actually going the wrong way, while $\log$ (DTC) remains economically significant as before.

The DTC measure used in our previous analysis is short ratio (SR) scaled by the average of this month's daily turnover ratio. We show that our results are robust to the horizon length over which we average daily turnover. For DTC2, we average daily turnover in the previous month. For DTC3, we use the past 6-months of data to calculate daily turnover. 
For DTC4, we use the past one-year of daily observations to calculate average daily turnover.

In Table 8, from column (1), notice that DTC2 still significantly and negatively forecast future returns while SR does not. The coefficient on DTC2 is -.0003 with a t-statistic of -1.82, similar to before. From columns (2) and (3), a similar conclusion holds for DTC3 and DTC4. In short, our DTC forecasting results are invariant to the lagged horizon over which we calculate average daily turnover.

\subsection{Controlling for Turnover, Illiquidity, Idiosyncratic Volatility and Analyst Forecast Dispersion}

In Table 9, we finally consider a number of alternative explanations for the power of DTC to forecast returns. Our primarily concern is that the literature has found that lagged turnover measured at different horizons forecasts stock returns.

First, our DTC or DTC2 results could be driven by the high volume return premium as documented in Gervais, Kaniel, and Mingelgrin (2001). They find stocks experiencing abnormal recent increases in trading volume this week have high average returns in subsequent weeks. Stocks experiencing abnormal increases in trading volume would have low DTC or DTC2 measure by construction, and that could contribute to the superiority of DTC over SR.

In column (1) and (2), we run a horse race between DTC and DTC2 with 1/Turnover and 1 /Turnover2, where Turnover and Turnover2 are the average daily turnover measured at the same horizon as the ones used to construct DTC and DTC2. ${ }^{12}$ The coefficient on $1 /$ Turnover and $1 /$ Turnover2 indeed comes in with the expected sign. Low turnover stocks do worst the next month, consistent with Gervais, Kaniel, and Mingelgrin (2001). But our DTC effect and this low turnover effect are different because SR is highly correlated with Turnover and so our DTC variable is not very correlated (just .09) with 1/Turnover.

Alternatively, we worry that our DTC3 and DTC4 results might be related to Amihud (2002), where share turnover is in the denominator and is typically measured using longer horizons of data going back as far as one year. So we control for the Amihud (2002) illiquidity

\footnotetext{
${ }^{12}$ We get the same results if we used Turnover and Turnover 2 in the specification instead.
} 
factor in column (3) and (4) and find that our results are largely unchanged. The coefficient on DTC3 is -.0004 and is statistically significant with a t-statistic of -7.20 . The coefficient on the illiquidity measure is not strong in this sample. A similar conclusion holds for DTC4.

In column (5) and (6), we consider a more simplified version of Amihud (2002) which is the inverse of turnover, 1/Turnover3 and 1/Turnover4, from Lou and Shu (2014). Again, we find that DTC3 and DTC4 remains economically and statistically significant. The coefficient is virtually unchanged. In this specification, the inverse of turnover weakly forecast stock returns. Yet, the power of DTC3 and DTC4 remain the same.

In column (7), we show that DTC captures the marginal cost associated with trading as opposed to fundamental risks as captured say idiosyncratic volatility or IVOL of Ang, Hodrick, Xing, and Zhang (2006). Another reason why we are interested in idiosyncratic volatility is that Stambaugh, Yu, and Yuan (2014) find that IVOL captures potential overpricing due to short-selling costs. We find again that the coefficient on DTC is unchanged when adding in IVOL to our regression. To the extent DTC again is capturing over-valuation, it might be driven by disagreement and binding short-sales constraints effects as measured by Diether, Malloy, and Scherbina (2002)'s analyst forecast dispersion. In column (8), we show DTC is not capturing the same effect as this over-valuation factor.

\section{Conclusion}

We show that days-to-cover (DTC), which divides short ratio by share turnover, is a theoretically well-motivated measure of arbitrageurs' opinion about a stock's over-valuation when trading costs vary across stocks. Since trading cost is inversely related to share turnover, DTC is then approximately the marginal cost of the shorts. At the arbitrageurs' optimum it equals the marginal benefit of the shorts, which is their opinion about over-valuation. Consistent with our model, DTC is a stronger predictor of poor stock returns than short ratio, which has been the traditional proxy for arbitrageur opinion. The DTC effect is distinct from the stock lending fee effect though it has comparable forecasting power. 


\section{Appendix}

\section{Endogenizing the lending fee $f$}

Now suppose that in addition to arbitrageurs and optimists there is a third type of traders, index funds, with portfolio choices that are insensitive to prices or payoff forecasts. We suppose that on aggregate these new type of agents hold $\nu$ shares for each agent of the other two types. Since we normalize the number of arbitrageurs plus optimists to 1 , index funds hold a total of $\nu$ shares, and the total number of shares is $\nu+1-\gamma$.

Index funds are the only suppliers of borrowed shares. We assume that the market clearing fee is given by

$$
f=f_{0}+f_{1} x
$$

where $x$ is the amount of shares borrowed, provided $x<\nu$.

As before the demand by each arbitrageurs is given by

$$
n_{a}=\frac{\mu_{a}+f-p_{0}}{c}<0 .
$$

Hence the total demand for shorting by arbitrageurs is:

$$
\gamma\left|n_{a}\right|=\gamma \frac{p_{0}-\mu_{a}-f}{c}
$$

or using equation (22), we get

$$
\gamma\left|n_{a}\right|=\frac{\gamma\left(p_{0}-\mu_{a}-f_{0}\right)}{\gamma f_{1}+c}
$$

Notice that this coincides with results on the text whenever $f_{1}=0$

Since index funds do not adjust their portfolio, the market clearing price for a given $f$ stays the same that is:

$$
p_{0}=(1-\gamma) \mu_{o}+\gamma \mu_{a}+\gamma f=\mu_{a}+(1-\gamma)\left(\mu_{o}-\mu_{a}\right)+\gamma f
$$


$f$ is now endogenous and in equilibrium

$$
p_{0}-\mu_{a}=\frac{\gamma f_{1}+c}{\gamma f_{1}+c-\gamma^{2} f_{1}}\left[(1-\gamma)\left(\mu_{o}-\mu_{a}\right)+\gamma f_{0}-\frac{\gamma^{2} f_{0} f_{1}}{\gamma f_{1}+c}\right]
$$

However for $\gamma$ small (i.e. $\gamma^{2} \sim 0$ ), $p_{0}-\mu_{a}$ is invariant to $c$. More precisely,

$$
p_{0}-\mu_{a}-(1-\gamma)\left(\mu_{o}-\mu_{a}\right)-\gamma f_{0}=\frac{\gamma^{2} f_{1}}{\gamma f_{1}+c-\gamma^{2} f_{1}}\left[(1-\gamma)\left(\mu_{o}-\mu_{a}\right)+(\gamma-1) f_{0}\right]
$$

Hence,

$$
p_{0}-\mu_{a}=(1-\gamma)\left(\mu_{o}-\mu_{a}\right)+\gamma f_{0}+\gamma^{2} f_{1} \Gamma\left(c, f_{0}, f_{1}, \gamma\right)
$$

with $\Gamma$ bounded.

On the other hand, short interest satisfies:

$$
S R=\frac{\gamma\left|n_{a}\right|}{1-\gamma+\nu}=\frac{\gamma\left(p_{0}-\mu_{a}-f_{0}\right)}{\left(\gamma f_{1}+c\right)(1-\gamma+\nu)}=\frac{(1-\gamma) \gamma\left(\mu_{o}-\mu_{a}-f_{0}\right)+\gamma^{3} f_{1} \Gamma\left(c, f_{0}, f_{1}, \gamma\right)}{\left(\gamma f_{1}+c\right)(1-\gamma+\nu)}
$$

Thus if $\gamma^{2}$ is small enough, $S R$ decrease with $c$.

Furthermore, since $f$ does not enter the optimization problem of the optimists, we still obtain that turnover $V$ equals

$$
\frac{1-\gamma}{2(1-\gamma+\nu)} \times \frac{\left(\delta \mu_{o}-p_{o}\right)}{c}
$$

Thus

$$
D T C=\frac{2 c\left[\gamma\left(\mu_{o}-\mu_{a}-f_{0}\right)+\gamma^{3} f \Gamma\right]}{\left(\gamma f_{1}+c\right)\left[(\delta-1) \mu_{o}+\gamma\left(\mu_{o}-\mu_{a}-f_{0}\right)-\gamma^{2} f_{1} \Gamma\right]}
$$

Notice that for any fixed $c>0 \frac{\partial \Gamma}{\partial \gamma}$ is bounded above.

Thus taking a first order expansion of DTC around $\gamma=0$ we obtain, as before,

$$
D T C \sim 2 \frac{\gamma\left(\mu_{o}-\mu_{a}-f_{0}\right)}{(\delta-1) \mu_{o}}
$$




\section{References}

Amihud, Y., 2002, "Illiquidity and stock returns: cross-section and time-series effects," Journal of financial markets, 5(1), 31-56.

Amihud, Y., H. Mendelson, and L. H. Pedersen, 2006, Liquidity and asset prices. Now Publishers Inc.

Ang, A., R. J. Hodrick, Y. Xing, and X. Zhang, 2006, "The cross-section of volatility and expected returns," The Journal of Finance, 61(1), 259-299.

Asquith, P., and L. K. Meulbroek, 1995, An empirical investigation of short interest. Division of Research, Harvard Business School.

Asquith, P., P. A. Pathak, and J. R. Ritter, 2005, "Short interest, institutional ownership, and stock returns," Journal of Financial Economics, 78(2), 243-276.

Beneish, M. D., C. Lee, and C. Nichols, 2013, "In short supply: Equity overvaluation and short selling," Rock Center for Corporate Governance at Stanford University Working Paper, (165).

Boehmer, E., C. M. Jones, and X. Zhang, 2008, "Which shorts are informed?," The Journal of Finance, 63(2), 491-527.

Brent, A., D. Morse, and E. K. Stice, 1990, "Short interest: Explanations and tests," Journal of Financial and Quantitative Analysis, 25(02), 273-289.

Carhart, M. M., 1997, "On persistence in mutual fund performance," The Journal of finance, $52(1), 57-82$.

Chen, J., H. Hong, and J. C. Stein, 2002, "Breadth of ownership and stock returns," Journal of financial Economics, 66(2), 171-205.

Cohen, L., K. B. Diether, and C. J. Malloy, 2007, "Supply and demand shifts in the shorting market," The Journal of Finance, 62(5), 2061-2096.

Daniel, K., M. Grinblatt, S. Titman, and R. Wermers, 1997, "Measuring mutual fund performance with characteristic-based benchmarks," The Journal of finance, 52(3), 1035-1058.

D'avolio, G., 2002, "The market for borrowing stock," Journal of Financial Economics, 66(2), 271-306. 
De Long, J. B., A. Shleifer, L. H. Summers, and R. J. Waldmann, 1990, "Noise trader risk in financial markets," Journal of political Economy, pp. 703-738.

Dechow, P. M., A. P. Hutton, L. Meulbroek, and R. G. Sloan, 2001, "Short-sellers, fundamental analysis, and stock returns," Journal of Financial Economics, 61(1), 77-106.

Diether, K. B., K.-H. Lee, and I. M. Werner, 2009, "Short-sale strategies and return predictability," Review of Financial Studies, 22(2), 575-607.

Diether, K. B., C. J. Malloy, and A. Scherbina, 2002, "Differences of opinion and the cross section of stock returns," The Journal of Finance, 57(5), 2113-2141.

Drechsler, I., and Q. F. Song, 2014, "The Shorting Premium and Asset Pricing Anomalies," Available at SSRN.

Duffie, D., N. Garleanu, and L. H. Pedersen, 2002, "Securities lending, shorting, and pricing," Journal of Financial Economics, 66(2), 307-339.

Engelberg, J. E., A. V. Reed, and M. C. Ringgenberg, 2012, "How are shorts informed?: Short sellers, news, and information processing," Journal of Financial Economics, 105(2), $260-278$.

Fama, E. F., and K. R. French, 1992, "The cross-section of expected stock returns," the Journal of Finance, 47(2), 427-465.

— , 1993, "Common risk factors in the returns on stocks and bonds," Journal of financial economics, 33(1), 3-56.

Fama, E. F., and J. D. MacBeth, 1973, "Risk, return, and equilibrium: Empirical tests," The Journal of Political Economy, pp. 607-636.

Figlewski, S., 1981, "The informational effects of restrictions on short sales: some empirical evidence," Journal of Financial and Quantitative Analysis, 16(04), 463-476.

Figlewski, S., and G. P. Webb, 1993, "Options, short sales, and market completeness," The Journal of Finance, 48(2), 761-777.

Gao, X., and J. R. Ritter, 2010, "The marketing of seasoned equity offerings," Journal of Financial Economics, 97(1), 33-52.

Geczy, C. C., D. K. Musto, and A. V. Reed, 2002, "Stocks are special too: An analysis of 
the equity lending market," Journal of Financial Economics, 66(2), 241-269.

Gervais, S., R. Kaniel, and D. H. Mingelgrin, 2001, "The high-volume return premium," The Journal of Finance, 56(3), 877-919.

Grossman, S. J., and M. H. Miller, 1988, "Liquidity and market structure," the Journal of Finance, 43(3), 617-633.

Hanson, S. G., and A. Sunderam, 2014, "The growth and limits of arbitrage: Evidence from short interest," Review of Financial Studies, 27(4), 1238-1286.

Harrison, J. M., and D. M. Kreps, 1978, "Speculative investor behavior in a stock market with heterogeneous expectations," The Quarterly Journal of Economics, pp. 323-336.

Hirshleifer, D., S. H. Teoh, and J. J. Yu, 2011, "Short arbitrage, return asymmetry, and the accrual anomaly," Review of Financial Studies, 24(7), 2429-2461.

Hong, H., J. D. Kubik, and T. Fishman, 2012, "Do arbitrageurs amplify economic shocks?," Journal of Financial Economics, 103(3), 454-470.

Hong, H., T. Lim, and J. C. Stein, 2000, "Bad news travels slowly: Size, analyst coverage, and the profitability of momentum strategies," The Journal of Finance, 55(1), 265-295.

Hong, H., J. Scheinkman, and W. Xiong, 2006, "Asset float and speculative bubbles," The journal of finance, 61(3), 1073-1117.

Hong, H., and J. C. Stein, 2003, "Differences of opinion, short-sales constraints, and market crashes," Review of financial studies, 16(2), 487-525.

Jegadeesh, N., and S. Titman, 1993, "Returns to buying winners and selling losers: Implications for stock market efficiency," The Journal of Finance, 48(1), 65-91.

Jones, C. M., and O. A. Lamont, 2002, "Short-sale constraints and stock returns," Journal of Financial Economics, 66(2), 207-239.

Lou, D., and C. Polk, 2013, Comomentum: Inferring arbitrage activity from return correlations. Paul Woolley Centre for the Study of Capital Market Dysfunctionality; Financial Markets Group.

Lou, X., and T. Shu, 2014, "Price Impact or Trading Volume: Why is the Amihud (2002) Illiquidity Measure Priced?," Available at SSRN 2291942. 
Miller, E. M., 1977, "Risk, uncertainty, and divergence of opinion," The Journal of Finance, 32(4), 1151-1168.

Nagel, S., 2005, "Short sales, institutional investors and the cross-section of stock returns," Journal of Financial Economics, 78(2), 277-309.

Newey, W. K., K. D. West, et al., 1987, "A Simple, Positive Semi-definite, Heteroskedasticity and Autocorrelation Consistent Covariance Matrix," Econometrica, 55(3), 703-08.

Ofek, E., M. Richardson, and R. F. Whitelaw, 2004, "Limited arbitrage and short sales restrictions: Evidence from the options markets," Journal of Financial Economics, 74(2), $305-342$.

Pastor, L., and R. F. Stambaugh, 2003, "LIQUIDITY RISK AND EXPECTED STOCK RETURNS," Journal of Political Economy, 111(3).

Saffi, P. A., and K. Sigurdsson, 2010, "Price efficiency and short selling," Review of Financial Studies, p. hhq124.

Scheinkman, J. A., and W. Xiong, 2003, "Overconfidence and speculative bubbles," Journal of political Economy, 111(6), 1183-1220.

Shleifer, A., and R. W. Vishny, 1997, "The limits of arbitrage," The Journal of Finance, $52(1), 35-55$.

Stambaugh, R. F., J. Yu, and Y. Yuan, 2012, "The short of it: Investor sentiment and anomalies," Journal of Financial Economics, 104(2), 288-302.

— 2014, "Arbitrage Asymmetry and the Idiosyncratic Volatility Puzzle," Available at SSRN 2155491.

Vayanos, D., 1998, "Transaction costs and asset prices: A dynamic equilibrium model," Review of financial studies, 11(1), 1-58.

Woolridge, J. R., and A. Dickinson, 1994, "Short selling and common stock prices," Financial Analysts Journal, pp. 20-28. 
Figure 1: Correlations between Short ratio (SR) and Turnover, 1988:01 to 2012:12

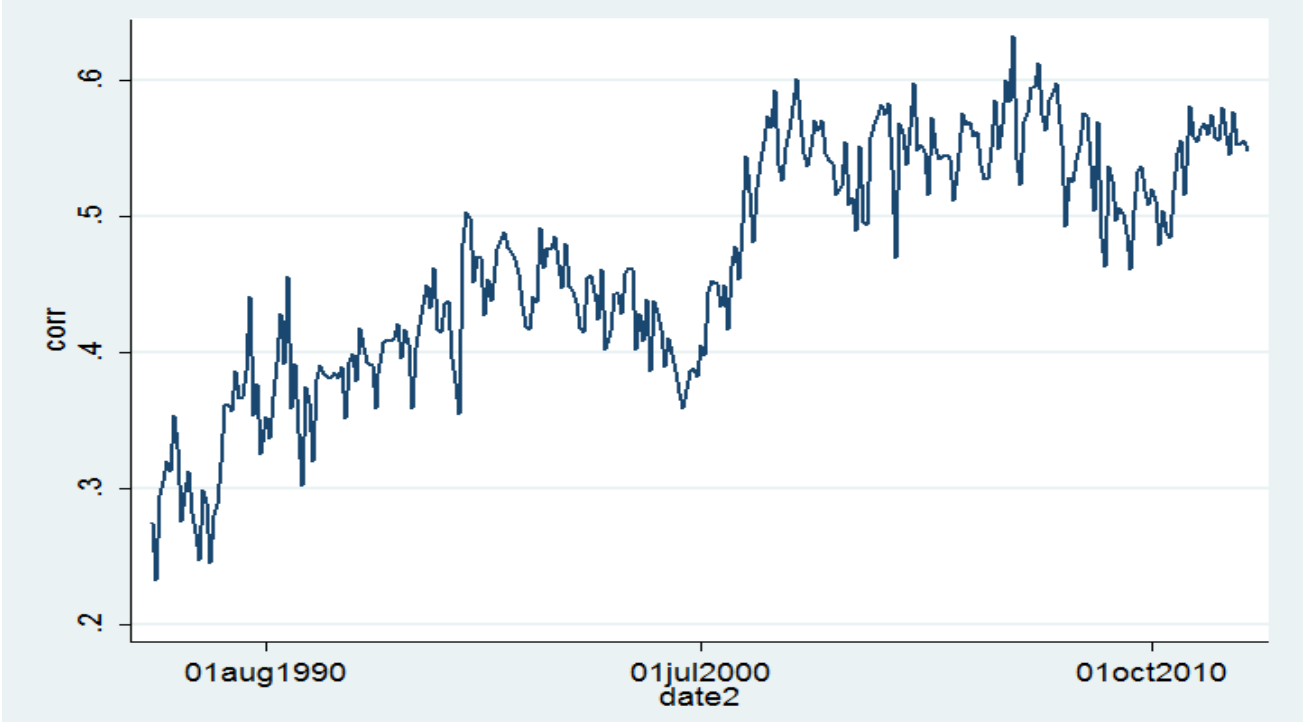

(a) Correlation of SR and Turnover

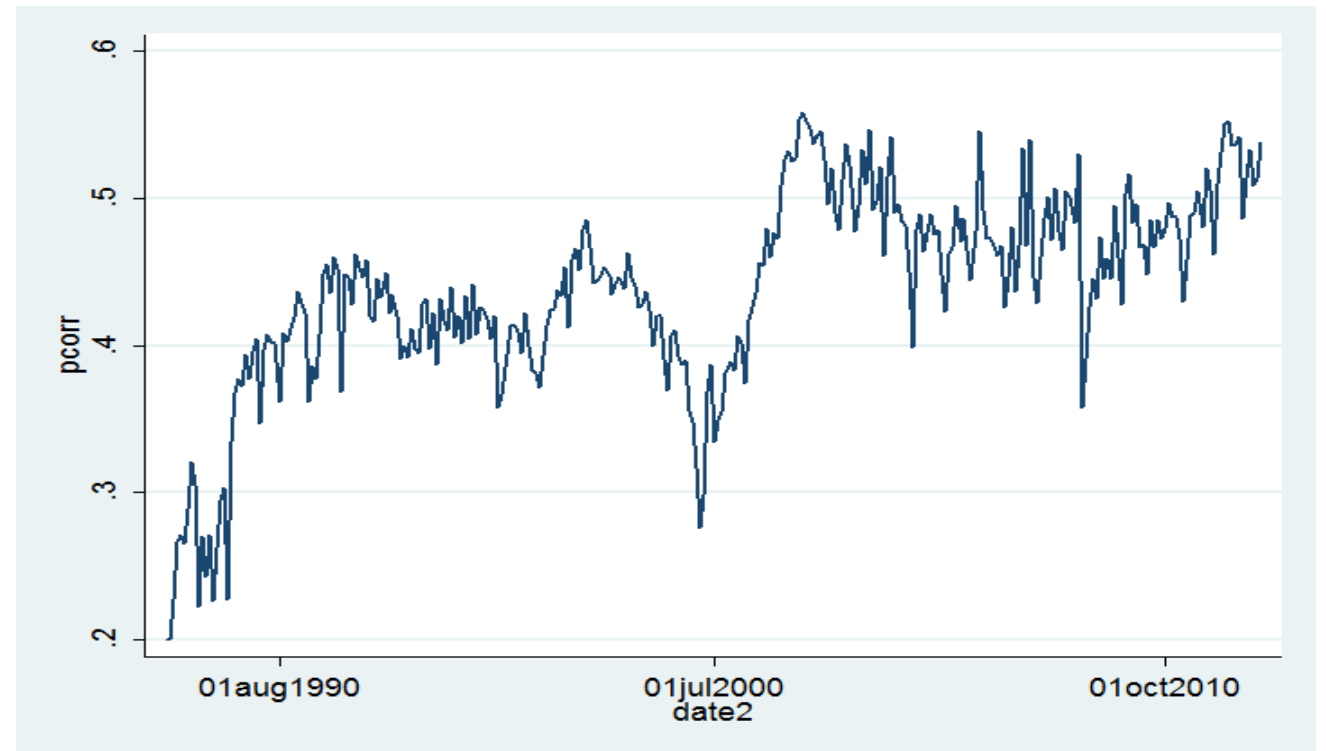

(b) Partial Correlation of SR and Turnover

This figure plots the cross-sectional correlation (Panel A) and partial correlation (Panel B) between short interest ratio (SR) and share turnover. The univariate correlation coefficient is computed in cross section every month and is plotted over time. The partial correlation between short interest ratio (SR) and share turnover is computed after controlling for size, book-to-market, past 12 months cumulative returns and institutional ownership. The sample period runs from January of 1988 to December of 2012. 
Figure 2: Time series of mean SR and DTC.

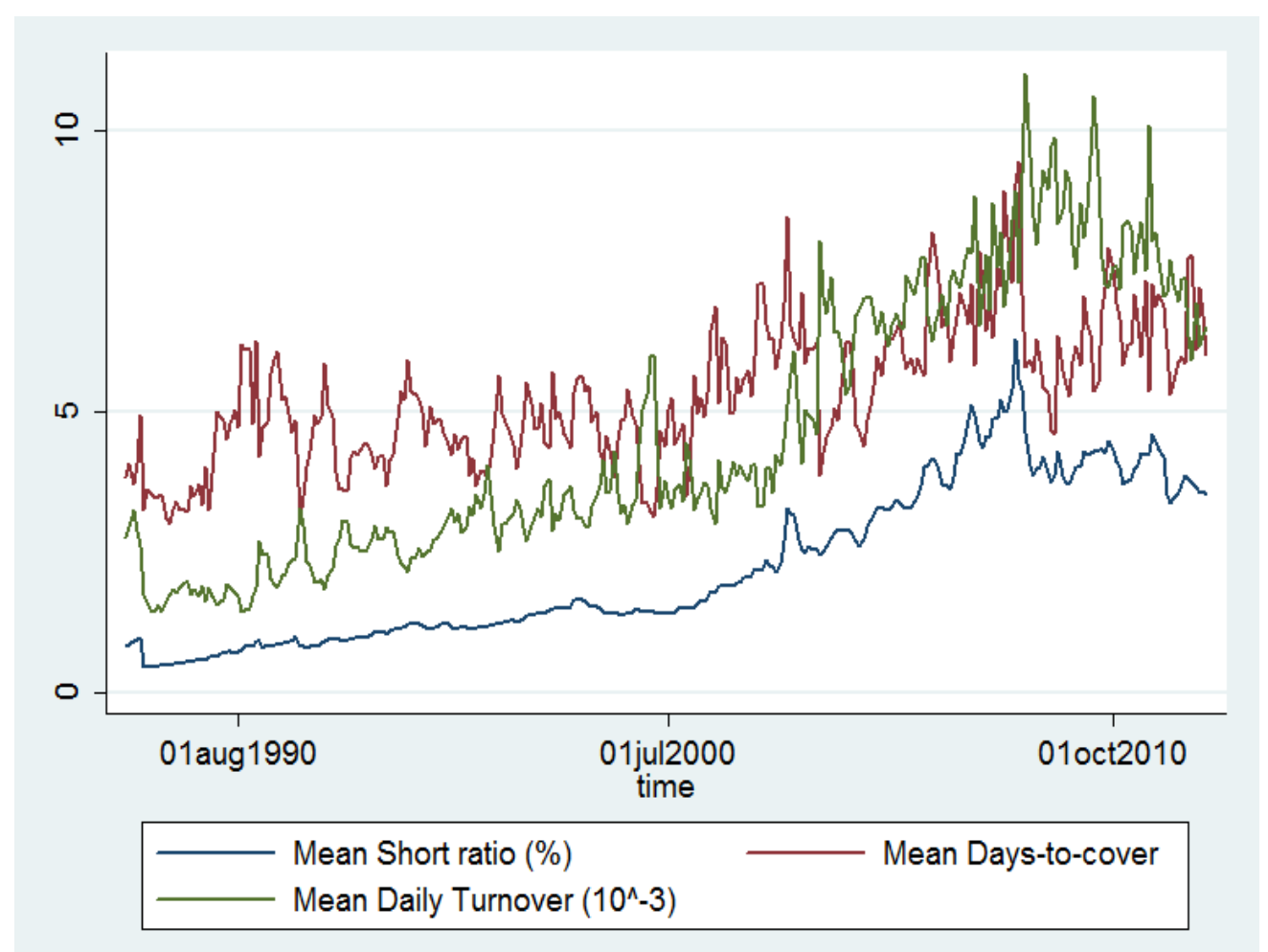

This figure plots the time-series of average short interest (SR) ratio (in percentage), days-to-cover (DTC) and daily turnover (scaled by 1000) from January 1988 to December 2012 based on all NYSE, Amex, and NASDAQ stocks. 
Figure 3: Decile Portfolio Performance

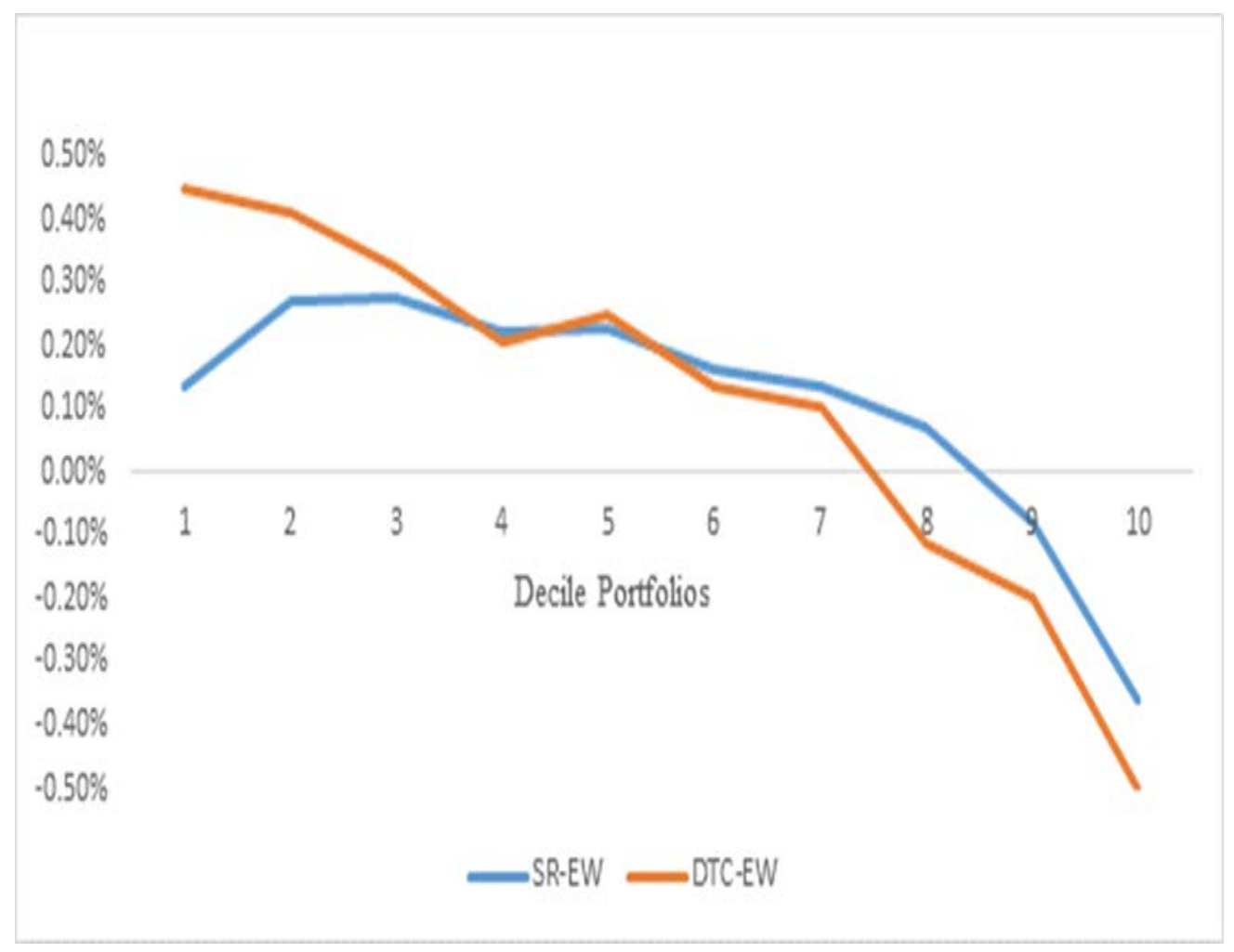

This figure shows the average DGTW-adjusted returns for decile portfolios sorted on short interest ratio (SR) and days-to-cover (DTC). Returns are equally weighted within each portfolio. The y-axis is monthly returns and $\mathrm{x}$-axis is the decile portfolio from low SR(DTC) to high SR(DTC). 
Figure 4: Cumulative returns to SR and DTC spread portfolio.

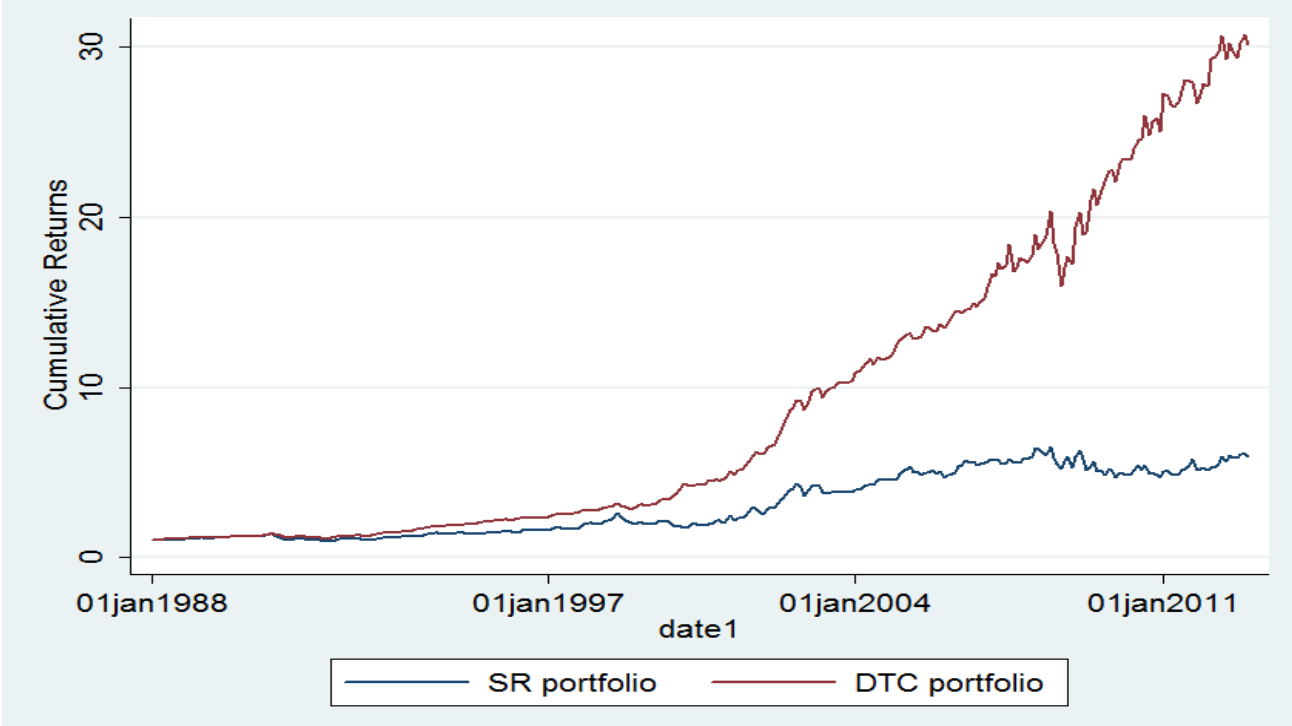

(a) Cumulative equal-weighted returns

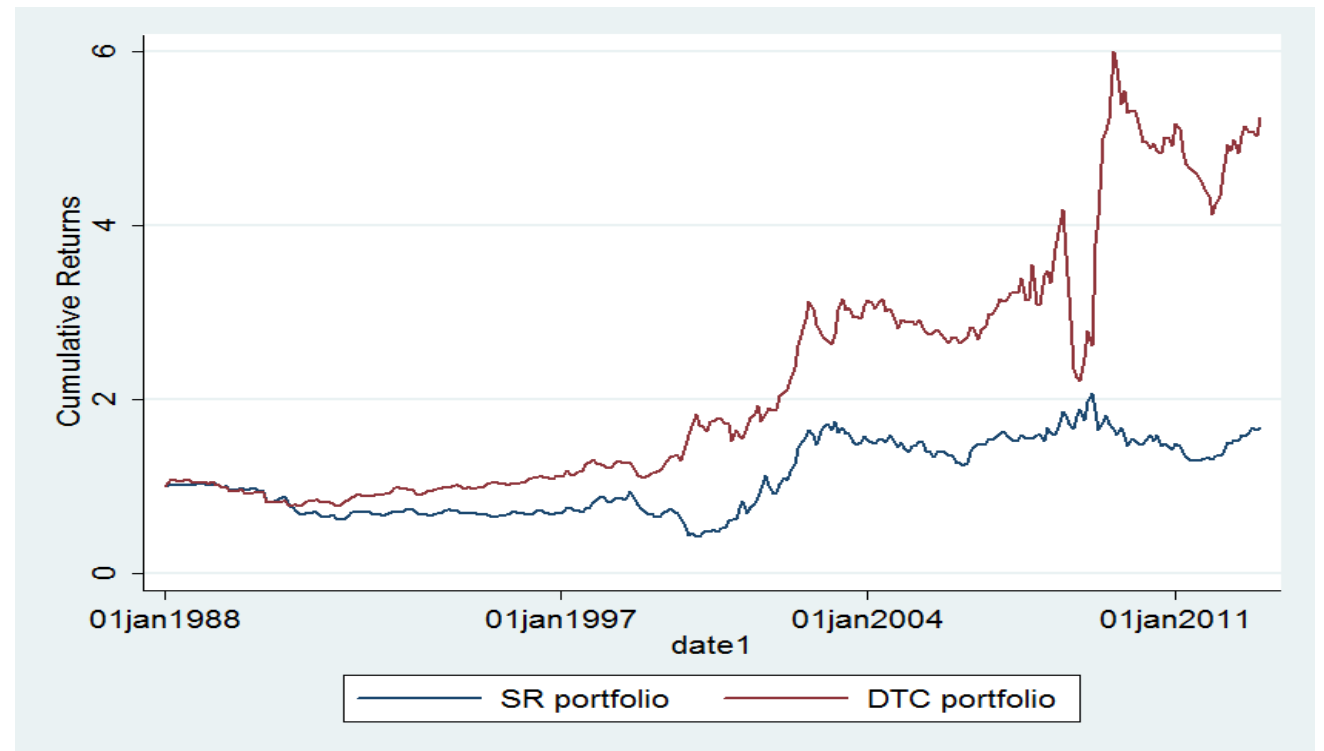

(b) Cumulative value-weighted returns

This figure plots the cumulative equal-weighted returns (Panel A) and value-weighted returns (Panel B) to the bottom-minus-top decile portfolio formed on short interest ratio (SR) and days-to-cover (DTC). The sample period runs from January of 1988 to December of 2012. 
Figure 5: Trailing ten-year Sharpe ratios of equal-weighted SR and DTC spread portfolio.

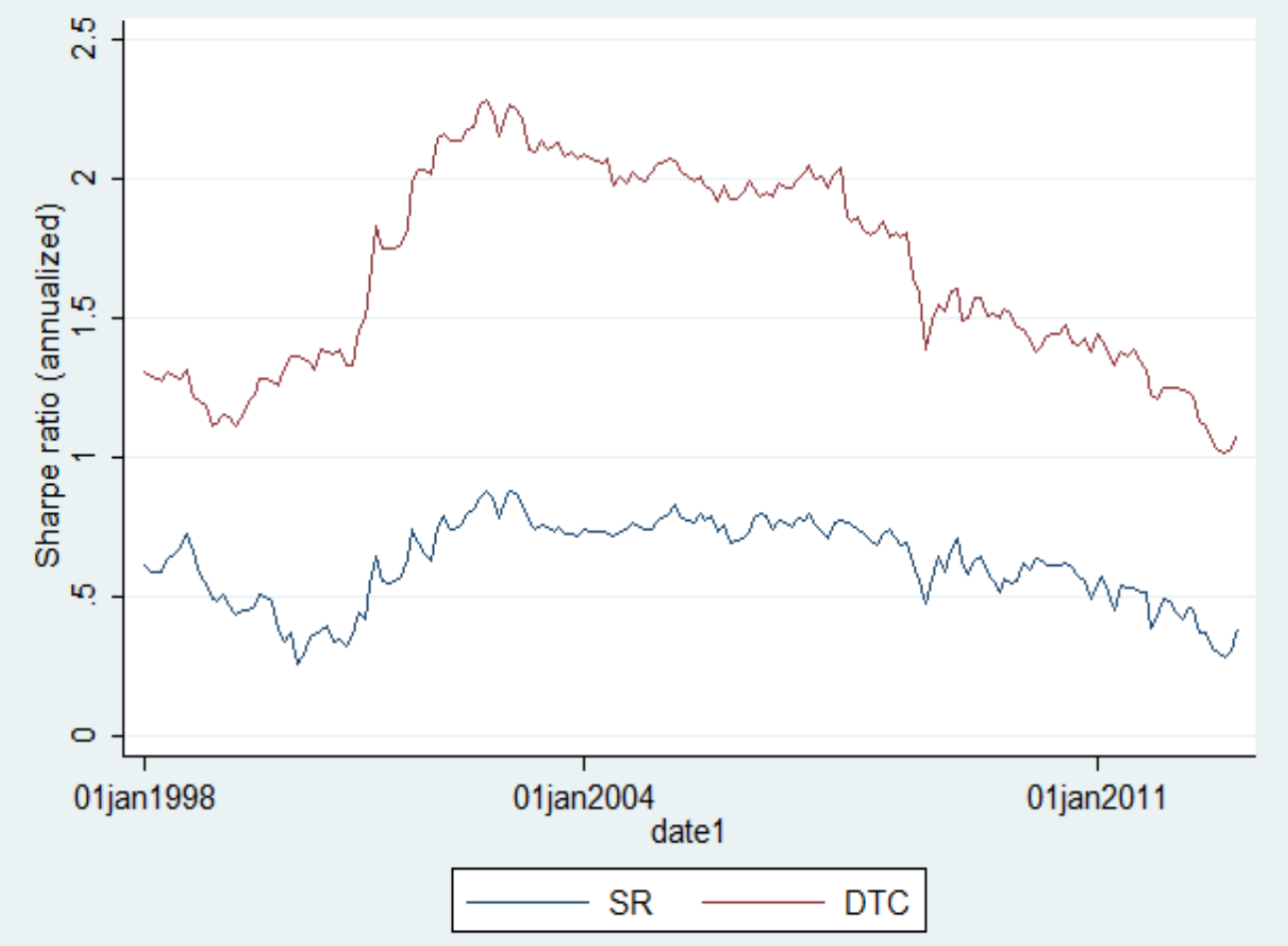

This figure plots the trailing ten-year performance to the bottom-minus-top decile portfolio formed on short interest ratio (SR) and days-to-cover (DTC). The sample period runs from January of 1988 to December of 2012 . 
Figure 6: Annual returns to equal-weighted SR and DTC spread portfolio.

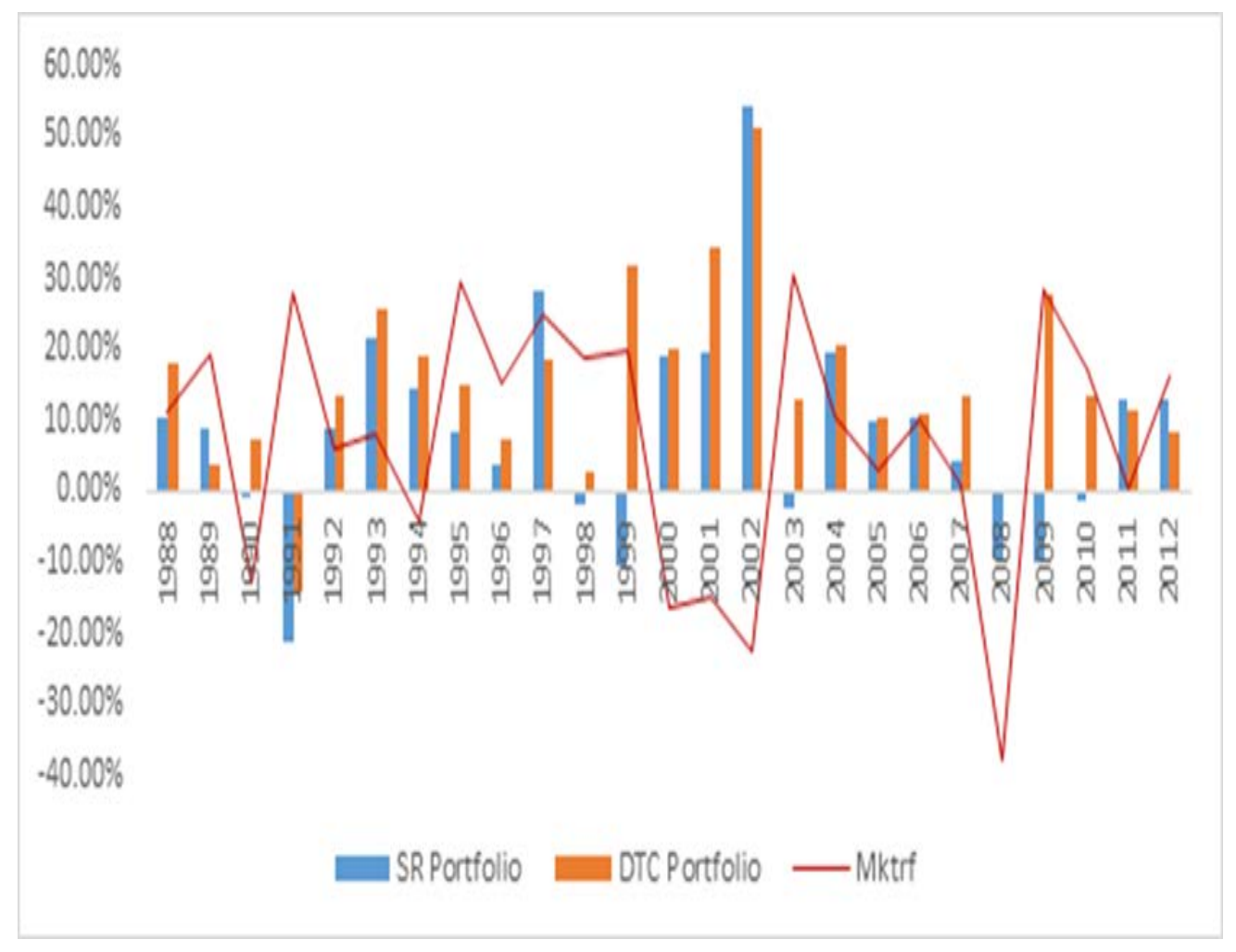

This figure shows the annual equal-weighted returns to the bottom-minus-top decile portfolio formed on short interest ratio (SR) and days-to-cover (DTC). We also plot the annual market excess return in this figure. The sample period runs from January of 1988 to December of 2012. 


\section{Table 1: Descriptive Statistics}

This table presents the summary statistics of the sample, including the mean and standard deviation for each variable, and the correlations among them. Short interest ratio (SR) is the shares shorted over total shares outstanding. Share turnover is the daily trading volume over total shares outstanding averaged within a given month. Days-to-cover (DTC) is short interest ratio (SR) over daily turnover. Institutional ownership (IO) is the sum of shares held by institutions from 13F filings in each quarter divided by shares outstanding. Market beta (Beta) is calculated from past five years' monthly return, following Fama and French (1992). Size (LnME) is the natural log of firm market capitalization at the end of the June of each year. Book-to-market $(\mathrm{LnBM})$ is the natural log of book-to-market ratio. The cases with negative book value are deleted. Momentum (MOM) is defined as the cumulative return from month t-12 to t-2. The short term reversal measure (REV) is the lagged monthly return. Panel A reports the summary statistics for the full sample and by market capitalization quintiles. Panel B reports these statistics for our sub-sample where we also have the lending fee data. Panel $\mathrm{C}$ reports the pairwise correlations among our variables where they overlap. Fee1 is the simple average fees of stock borrowing transactions from hedge funds in a given security, which is the difference between the risk-free rate and the rebate rate. Fee2 is a score from 1 to 10 created by Markit using their proprietary information meant to capture the cost of borrowing the stock. Here 1 is the cheapest to short and 10 the most difficult. Fee1 is available since November of 2006 and fee2 is available since October of 2003. The overall sample period runs from January of 1988 to December 2012.

Panel A: Summary Statistics-Full Sample

\begin{tabular}{|c|c|c|c|c|c|c|c|}
\hline Variables & & All Firms & Quintile 1 & Quintile 2 & Quintile 3 & Quintile 4 & Quintile 5 \\
\hline \multirow[t]{2}{*}{ Short Ratio (SR) } & Mean & $2.26 \%$ & $1.59 \%$ & $3.51 \%$ & $3.48 \%$ & $2.92 \%$ & $1.87 \%$ \\
\hline & Std. & $3.65 \%$ & $3.32 \%$ & $4.59 \%$ & $4.16 \%$ & $3.23 \%$ & $1.97 \%$ \\
\hline \multirow[t]{2}{*}{ Turnover } & Mean & $0.46 \%$ & $0.32 \%$ & $0.55 \%$ & $0.66 \%$ & $0.71 \%$ & $0.60 \%$ \\
\hline & Std. & $0.61 \%$ & $0.51 \%$ & $0.63 \%$ & $0.71 \%$ & $0.72 \%$ & $0.59 \%$ \\
\hline \multirow[t]{2}{*}{ Days to Cover (DTC) } & Mean & 5.45 & 5.08 & 7.16 & 6.27 & 5.32 & 3.94 \\
\hline & Std. & 8.26 & 9.03 & 9.06 & 7.24 & 5.99 & 3.92 \\
\hline \multirow[t]{2}{*}{ Institutional Ownership (IO) } & Mean & $42.04 \%$ & $27.36 \%$ & $52.85 \%$ & $59.52 \%$ & $63.43 \%$ & $63.02 \%$ \\
\hline & Std. & $28.99 \%$ & $24.85 \%$ & $26.29 \%$ & $24.56 \%$ & $21.94 \%$ & $17.70 \%$ \\
\hline \multirow[t]{2}{*}{ Market Beta (Beta) } & Mean & 1.30 & 1.40 & 1.32 & 1.22 & 1.14 & 1.00 \\
\hline & Std. & 1.06 & 1.21 & 0.96 & 0.85 & 0.74 & 0.66 \\
\hline \multirow[t]{2}{*}{ Size (LnME) } & Mean & 5.51 & 3.96 & 5.97 & 6.88 & 7.80 & 9.39 \\
\hline & Std. & 2.14 & 1.25 & 0.62 & 0.56 & 0.55 & 1.00 \\
\hline \multirow[t]{2}{*}{ Book-to-market (LnBM) } & Mean & -0.61 & -0.44 & -0.70 & -0.78 & -0.85 & -1.01 \\
\hline & Std. & 0.89 & 0.94 & 0.78 & 0.75 & 0.75 & 0.80 \\
\hline \multirow[t]{2}{*}{ Reversal (REV) } & Mean & $1.21 \%$ & $1.22 \%$ & $1.22 \%$ & $1.25 \%$ & $1.22 \%$ & $1.07 \%$ \\
\hline & Std. & $17.47 \%$ & $20.80 \%$ & $14.41 \%$ & $12.99 \%$ & $11.54 \%$ & $9.86 \%$ \\
\hline \multirow[t]{2}{*}{ Momentum (MOM) } & Mean & $13.92 \%$ & $11.21 \%$ & $17.56 \%$ & $18.12 \%$ & $16.84 \%$ & $15.04 \%$ \\
\hline & Std. & $73.22 \%$ & $84.79 \%$ & $63.57 \%$ & $62.10 \%$ & $53.18 \%$ & $41.35 \%$ \\
\hline \# of Obs. & & 906377 & 483318 & 142346 & 102408 & 90635 & 87670 \\
\hline
\end{tabular}


Table 1 Continued

Panel B: Summary Statistics - Sample with Lending Fee data

\begin{tabular}{|c|c|c|c|c|c|c|c|}
\hline Variables & & All Firms & Quintile 1 & Quintile 2 & Quintile 3 & Quintile 4 & Quintile 5 \\
\hline \multirow[t]{2}{*}{ Short Ratio (SR) } & Mean & $4.32 \%$ & $3.47 \%$ & $7.06 \%$ & $6.10 \%$ & $4.36 \%$ & $2.46 \%$ \\
\hline & Std. & $4.71 \%$ & $4.60 \%$ & $5.27 \%$ & $4.87 \%$ & $3.72 \%$ & $2.17 \%$ \\
\hline \multirow[t]{2}{*}{ Turnover } & Mean & $0.80 \%$ & $0.54 \%$ & $0.99 \%$ & $1.15 \%$ & $1.19 \%$ & $0.96 \%$ \\
\hline & Std. & $0.82 \%$ & $0.70 \%$ & $0.83 \%$ & $0.92 \%$ & $0.90 \%$ & $0.72 \%$ \\
\hline \multirow[t]{2}{*}{ Days to Cover (DTC) } & Mean & 6.85 & 7.59 & 9.03 & 6.63 & 4.46 & 2.98 \\
\hline & Std. & 7.37 & 8.75 & 6.61 & 5.20 & 3.73 & 2.28 \\
\hline \multirow[t]{2}{*}{ Institutional Ownership (IO) } & Mean & $58.71 \%$ & $43.90 \%$ & $72.73 \%$ & $75.57 \%$ & $76.65 \%$ & $71.83 \%$ \\
\hline & Std. & $28.34 \%$ & $27.51 \%$ & $22.83 \%$ & $20.92 \%$ & $17.64 \%$ & $14.37 \%$ \\
\hline \multirow[t]{2}{*}{ Market Beta (Beta) } & Mean & 1.31 & 1.44 & 1.31 & 1.24 & 1.16 & 0.97 \\
\hline & Std. & 0.99 & 1.10 & 0.96 & 0.87 & 0.79 & 0.67 \\
\hline \multirow[t]{2}{*}{ Size (LnME) } & Mean & 6.38 & 4.85 & 6.67 & 7.50 & 8.33 & 9.93 \\
\hline & Std. & 1.95 & 1.01 & 0.34 & 0.30 & 0.35 & 0.86 \\
\hline \multirow[t]{2}{*}{ Book-to-market (LnBM) } & Mean & -0.64 & -0.48 & -0.69 & -0.75 & -0.85 & -0.99 \\
\hline & Std. & 0.83 & 0.87 & 0.73 & 0.73 & 0.73 & 0.75 \\
\hline \multirow[t]{2}{*}{ Reversal (REV) } & Mean & $1.10 \%$ & $1.09 \%$ & $1.27 \%$ & $1.20 \%$ & $1.06 \%$ & $0.82 \%$ \\
\hline & Std. & $14.04 \%$ & $16.42 \%$ & $12.64 \%$ & $11.25 \%$ & $10.32 \%$ & $8.96 \%$ \\
\hline \multirow[t]{2}{*}{ Momentum (MOM) } & Mean & $12.75 \%$ & $10.39 \%$ & $15.66 \%$ & $16.31 \%$ & $16.36 \%$ & $12.19 \%$ \\
\hline & Std. & $66.89 \%$ & $82.48 \%$ & $52.39 \%$ & $47.27 \%$ & $43.00 \%$ & $32.66 \%$ \\
\hline \multirow[t]{2}{*}{ Fee1 (basis point) } & Mean & 48.10 & 73.04 & 48.20 & 39.96 & 33.11 & 28.74 \\
\hline & Std. & 91.44 & 128.92 & 89.10 & 75.83 & 53.89 & 34.29 \\
\hline \multirow[t]{2}{*}{ Fee2 (score) } & Mean & 1.39 & 1.63 & 1.20 & 1.12 & 1.07 & 1.13 \\
\hline & Std. & 3.56 & 1.42 & 0.85 & 0.64 & 0.43 & 0.17 \\
\hline \# of Obs. & & 279891 & 142429 & 43499 & 32639 & 30392 & 30932 \\
\hline
\end{tabular}


Table 1 Continued

Panel C: Correlations

\begin{tabular}{|c|c|c|c|c|c|c|c|c|c|c|c|}
\hline & SR & Turnover & DTC & $\mathrm{IO}$ & Beta & LnME & LnBM & Rev & Mom & Fee1 & Fee2 \\
\hline SR & 1.00 & & & & & & & & & & \\
\hline Turnover & 0.69 & 1.00 & & & & & & & & & \\
\hline DTC & 0.83 & 0.21 & 1.00 & & & & & & & & \\
\hline $\mathrm{IO}$ & 0.57 & 0.59 & 0.33 & 1.00 & & & & & & & \\
\hline Beta & 0.13 & 0.22 & 0.01 & 0.02 & 1.00 & & & & & & \\
\hline LnME & 0.53 & 0.49 & 0.36 & 0.71 & -0.11 & 1.00 & & & & & \\
\hline LnBM & -0.29 & -0.27 & -0.19 & -0.17 & -0.11 & -0.30 & 1.00 & & & & \\
\hline Rev & 0.01 & 0.07 & -0.02 & 0.04 & -0.03 & 0.05 & 0.02 & 1.00 & & & \\
\hline Mom & 0.02 & 0.09 & -0.04 & 0.11 & -0.05 & 0.14 & 0.03 & 0.03 & 1.00 & & \\
\hline Fee1 & 0.18 & 0.01 & 0.17 & -0.19 & 0.10 & -0.27 & -0.02 & -0.07 & -0.06 & 1.00 & \\
\hline Fee2 & -0.03 & -0.12 & 0.04 & -0.39 & 0.08 & -0.34 & -0.03 & -0.07 & -0.18 & 0.42 & 1.00 \\
\hline
\end{tabular}




\section{Table 2: Returns to portfolio strategies based on Short Interest Ratio (SR)}

This table provides portfolio returns and alphas, sorted on Short Interest Ratio (SR). At the end of each month, all the stocks are sorted into deciles based on short interest ratio and a long-short portfolio is formed by buying the lowest decile and shorting the highest decile portfolio. Portfolio returns are computed over the next month. We report the excess returns, characteristics-adjusted abnormal returns calculated following Daniel, Grinblatt, Titman and Wermers (1997), denoted as DGTW, four-factor alpha (following Carhart (1997)) and five-factor adjusted alpha (Carhart 4-factor augmented by Pastor and Stambaugh's (2003) liquidity factor). Sharpe ratios are annualized. The sample runs from January 1988 to December 2012. Panel A reports the results for the equal-weighted returns and panel B reports value-weighted returns.

Panel A: Equal-weighted Portfolio Returns

\begin{tabular}{|c|c|c|c|c|}
\hline & Excess Return & DGTW Adjusted Return & Four-factor Alpha & Five-factor Alpha \\
\hline Mean & $0.71 \%$ & $0.49 \%$ & $1.00 \%$ & $0.97 \%$ \\
\hline t-stat & $(2.57)$ & $(1.95)$ & $(6.19)$ & $(5.96)$ \\
\hline Std.Dev. & $4.75 \%$ & $4.39 \%$ & & \\
\hline Sharpe Ratio & 0.51 & 0.39 & & \\
\hline Skewness & -0.30 & -0.49 & & \\
\hline Kurtosis & 0.24 & 1.24 & & \\
\hline No. of obs & 300 & 300 & & \\
\hline
\end{tabular}

Panel B: Value-weighted Portfolio Returns

\begin{tabular}{ccccc}
\hline & Excess Return & DGTW Adjusted Return & Four-factor Alpha & Five-factor Alpha \\
\hline Mean & $0.29 \%$ & $0.22 \%$ & $0.49 \%$ & $0.43 \%$ \\
t-stat & $(0.99)$ & $(0.85)$ & $(2.32)$ & $(2.06)$ \\
Std.Dev. & $5.13 \%$ & $4.58 \%$ & & \\
Sharpe Ratio & 0.20 & 0.18 & \\
Skewness & -0.11 & -0.51 & \\
Kurtosis & 2.53 & 3.97 & \\
No. of obs & 300 & 300 & & \\
\hline \hline
\end{tabular}




\section{Table 3: Returns to portfolio strategies based on Days-to-Cover (DTC)}

This table provides portfolio returns and alphas, sorted on Days-to-Cover (DTC). At the end of each month, all the stocks are sorted into deciles based on days-to-cover and a long-short portfolio is formed by buying the lowest decile and shorting the highest decile portfolio. Portfolio returns are computed over the next month. We report the excess returns, characteristics-adjusted abnormal returns calculated following Daniel, Grinblatt, Titman and Wermers (1997), denoted as DGTW, four-factor alpha (following Carhart (1997)) and five-factor adjusted alpha (Carhart 4-factor augmented by Pastor and Stambaugh's (2003) liquidity factor). Sharpe ratios are annualized. The sample runs from January 1988 to December 2012. Panel A reports the results for the equal-weighted returns and panel B reports value-weighted returns.

\section{Panel A: Equal-weighted Portfolio Returns}

\begin{tabular}{ccccc}
\hline & Excess Return & DGTW Adjusted Return & Four-factor Alpha & Five-factor Alpha \\
\hline Mean & $1.19 \%$ & $0.95 \%$ & $1.35 \%$ & $1.31 \%$ \\
t-stat & $(6.67)$ & $(5.93)$ & $(8.32)$ & $(8.04)$ \\
Std.Dev. & $3.09 \%$ & $2.77 \%$ & & \\
Sharpe Ratio & 1.33 & 1.19 & & \\
Skewness & -0.30 & -0.30 & & \\
Kurtosis & 1.70 & 2.46 & & \\
No. of obs & 300 & 300 & & \\
\hline
\end{tabular}

Panel B: Value-weighted Portfolio Returns

\begin{tabular}{ccccc}
\hline & Excess Return & DGTW Adjusted Return & Four-factor Alpha & Five-factor Alpha \\
\hline Mean & $0.67 \%$ & $0.59 \%$ & $0.72 \%$ & $0.79 \%$ \\
t-stat & $(2.24)$ & $(2.56)$ & $(2.39)$ & $(2.60)$ \\
Std.Dev. & $5.16 \%$ & $3.97 \%$ & & \\
Sharpe Ratio & 0.45 & 0.51 & & \\
Skewness & 1.96 & 1.50 & & \\
Kurtosis & 20.93 & 16.40 & & \\
No. of obs & 300 & 300 & & \\
\hline \hline
\end{tabular}




\section{Table 4: Robustness of Portfolio Sorts}

This table reports portfolio sorting results for various robustness checks. The first set of results look at two sub-periods: one from 1988 to 1999 and one from 2000 to 2012. In the second set of results, we separately examine stocks listed on NYSE-Amex versus stocks listed on NASDAQ. In the third set of results, we sorted stocks based on SR and DTC into five and twenty portfolios instead of deciles. In the fourth set of results, we drop all the micro-cap stocks whose market capitalization are in the bottom decile/quintile of all the NYSE stocks. Lastly, we exclude the stocks with beginning period of price lower than $\$ 5$. The sample period runs from January of 1988 to December 2012. Reported are the equal-weighted DGTW-adjusted abnormal returns of a long-short portfolio that long in stocks of lowest SR or DTC and short in stocks of highest SR or DTC. We report the return differences between DTC and SR spread portfolio in the right-most column.

\begin{tabular}{|c|c|c|c|c|}
\hline & & SR & DTC & DTC - SR \\
\hline \multirow[t]{3}{*}{ Full Sample } & Equal-weight & $0.49 \%$ & $0.95 \%$ & $0.46 \%$ \\
\hline & t-stat & $(1.95)$ & $(5.93)$ & $(2.65)$ \\
\hline & $\begin{array}{l}\text { Value-weight } \\
\text { t-stat }\end{array}$ & $\begin{array}{l}0.22 \% \\
(0.85)\end{array}$ & $\begin{array}{l}0.59 \% \\
(2.56)\end{array}$ & $\begin{array}{l}0.50 \% \\
(1.18)\end{array}$ \\
\hline \multirow[t]{4}{*}{ Subperiod } & 1988/01-1999/12 & $0.41 \%$ & $0.79 \%$ & $0.37 \%$ \\
\hline & t-stat & $(1.42)$ & $(4.38)$ & $(1.90)$ \\
\hline & $2000 / 01-2012 / 12$ & $0.57 \%$ & $1.10 \%$ & $0.53 \%$ \\
\hline & t-stat & $(1.40)$ & $(4.25)$ & $(1.92)$ \\
\hline \multirow[t]{4}{*}{ Stock Exchanges } & NYSE-Amex & $0.54 \%$ & $0.96 \%$ & $0.41 \%$ \\
\hline & t-stat & $(2.65)$ & $(6.49)$ & $(2.85)$ \\
\hline & Nasdaq & $0.14 \%$ & $0.76 \%$ & $0.62 \%$ \\
\hline & t-stat & $(0.41)$ & $(3.00)$ & $(2.38)$ \\
\hline \multirow[t]{4}{*}{ Alternative sorts } & 5 portfolios & $0.42 \%$ & $0.78 \%$ & $0.36 \%$ \\
\hline & t-stat & $(1.97)$ & $(6.04)$ & $(2.55)$ \\
\hline & 20 portfolios & $0.67 \%$ & $1.26 \%$ & $0.59 \%$ \\
\hline & t-stat & $(2.31)$ & $(7.44)$ & $(2.21)$ \\
\hline \multirow[t]{4}{*}{ Remove micro-cap stocks } & Bottom $10 \%$ of NYSE size cutoff & $0.55 \%$ & $0.84 \%$ & $0.29 \%$ \\
\hline & t-stat & $(2.59)$ & (6.14) & $(1.76)$ \\
\hline & Bottom $20 \%$ of NYSE size cutoff & $0.53 \%$ & $0.79 \%$ & $0.25 \%$ \\
\hline & t-stat & $(2.67)$ & $(6.71)$ & $(1.43)$ \\
\hline \multirow[t]{2}{*}{ Alternative price filter } & price $>=5 \$$ & $0.23 \%$ & $0.59 \%$ & $0.36 \%$ \\
\hline & t-stat & $(0.90)$ & $(3.55)$ & $(2.17)$ \\
\hline
\end{tabular}




\section{Table 5: Fama-MacBeth Regressions of Monthly Returns on SR and DTC}

This table reports results from Fama-Macbeth (1973) regression of monthly stock returns on SR and/or DTC. Short interest ratio (SR) is the shares shorted over total shares outstanding. Days-to-cover (DTC) is short interest ratio (SR) over daily turnover. Market beta (Beta) is calculated from past five years' monthly return, following Fama and French (1992). Size (LnME) is the natural log of firm market capitalization at the end of the June of each year. Book-to-market (LnBM) is the natural log of book-to-market ratio. The cases with negative book value are deleted. Momentum (MOM) is defined as the cumulative return from month t-12 to t-2. The short term reversal measure (REV) is the lagged monthly return. Panel A reports regression results for the whole sample. Panel B reports regression results for two subperiods, one runs from 1988 to 1999 and the other one runs from 2000 to 2012. All the t-statistics are Newey and West (1987) adjusted to control for heteroskedasticity and autocorrelation. ${ }^{* * *}, * *$, and ${ }^{*}$ stands for significance level of $1 \%, 5 \%$ and $10 \%$, respectively.

Panel A: Fama-Macbeth Regression-Full Sample

\begin{tabular}{cccc}
\hline & Model $(1)$ & Model $(2)$ & Model $(3)$ \\
\hline SR & $-0.0985^{* * *}$ & & $-0.0431^{*}$ \\
& $(-5.77)$ & $-1.96)$ \\
DTC & & $(-9.55)$ & $-0.0003^{* * *}$ \\
& & $-5.49)$ \\
Beta & $0.0027^{*}$ & 0.0024 & 0.0025 \\
& $(1.76)$ & $(1.53)$ & $(1.64)$ \\
LnME & -0.0009 & $-0.0010^{*}$ & $-0.0010^{*}$ \\
& $(-1.58)$ & $(-1.89)$ & $(-1.75)$ \\
LnBM & $0.0025^{* * *}$ & $0.0027^{* * *}$ & $0.0025^{* * *}$ \\
& $(2.94)$ & $(3.05)$ & $(3.00)$ \\
Rev & $-0.0492^{* * *}$ & $-0.0494^{* * *}$ & $-0.0495^{* * *}$ \\
& $(-10.72)$ & $(-10.75)$ & $(-10.76)$ \\
Mom & 0.0011 & 0.0008 & 0.0009 \\
& $(0.53)$ & $(0.37)$ & $(0.41)$ \\
Ave.R-sq & 0.044 & 0.043 & 0.046 \\
N.of Obs. & 906377 & 906377 & 906377 \\
\hline \hline
\end{tabular}


Table 5 Continued

Panel B: Fama-Macbeth Regression-Subperiod Analysis

\begin{tabular}{ccccccc}
\hline & \multicolumn{2}{c}{ Sample Period: 1988 to 1999 } & \multicolumn{2}{c}{ Sample Period: 2000 to 2012 } \\
\hline & Model $(1)$ & Model $(2)$ & Model $(3)$ & Model $(1)$ & Model $(2)$ & Model $(3)$ \\
\hline SR & $-0.1364^{* * *}$ & & $-0.0674^{*}$ & $-0.0635^{* * *}$ & & -0.0207 \\
& $(-4.91)$ & & $(-1.77)$ & $(-3.32)$ & & $(-0.94)$ \\
DTC & & $-0.0004^{* * *}$ & $-0.0003^{* * *}$ & & $-0.0004^{* * *}$ & $-0.0004^{* * *}$ \\
& & $(-10.17)$ & $(-3.99)$ & & $(-5.83)$ & $(-4.15)$ \\
Beta & $0.0033^{*}$ & $0.0030^{*}$ & $0.0031^{*}$ & 0.0021 & 0.0018 & 0.0019 \\
& $(1.86)$ & $(1.66)$ & $(1.79)$ & $(0.89)$ & $(0.74)$ & $(0.79)$ \\
LnME & -0.0009 & -0.0010 & -0.0009 & -0.0009 & -0.0011 & -0.0010 \\
& $(-1.14)$ & $(-1.27)$ & $(-1.18)$ & $(-1.22)$ & $(-1.54)$ & $(-1.42)$ \\
LnBM & $0.0025^{* *}$ & $0.0026^{* *}$ & $0.0025^{* *}$ & $0.0026^{* *}$ & $0.0027^{* *}$ & $0.0026^{* *}$ \\
& $(2.01)$ & $(2.09)$ & $(2.03)$ & $(2.37)$ & $(2.45)$ & $(2.43)$ \\
Rev & $-0.0592^{* * *}$ & $-0.0597^{* * *}$ & $-0.0597^{* * *}$ & $-0.0399^{* * *}$ & $-0.0399^{* * *}$ & $-0.0400^{* * *}$ \\
& $(-10.46)$ & $(-10.52)$ & $(-10.55)$ & $(-5.99)$ & $(-5.98)$ & $(-5.98)$ \\
Mom & $0.0065^{* * *}$ & $0.0062^{* * *}$ & $0.0063^{* * *}$ & -0.0039 & -0.0042 & -0.0041 \\
& $(4.07)$ & $(3.85)$ & $(3.92)$ & $(-1.07)$ & $(-1.16)$ & $(-1.13)$ \\
Ave.R-sq & 0.036 & 0.034 & 0.037 & 0.056 & 0.055 & 0.058 \\
N.of Obs. & 441993 & 441993 & 441993 & 531429 & 531429 & 531429 \\
\hline \hline
\end{tabular}




\section{Table 6: Fama-MacBeth Regressions of Monthly Returns on SR and DTC- Controlling for Lending Fees}

This table reports results from Fama-Macbeth (1973) regression of monthly stock returns on SR and/or DTC, after controlling stock lending fees. Short interest ratio (SR) is the shares shorted over total shares outstanding. Days-to-cover (DTC) is short interest ratio (SR) over daily turnover. Market beta (Beta) is calculated from past five years' monthly return, following Fama and French (1992). Size (LnME) is the natural $\log$ of firm market capitalization at the end of the June of each year. Book-to-market (LnBM) is the natural log of book-to-market ratio. The cases with negative book value are deleted. Momentum (MOM) is defined as the cumulative return from month t-12 to t-2. The short term reversal measure (REV) is the lagged monthly return. Institutional ownership (IO) is the sum of shares held by institutions from $13 \mathrm{~F}$ filings in each quarter divided by shares outstanding. Fee1 is the simple average fees of stock borrowing transactions from hedge funds in a given security, which is the difference between the risk-free rate and the rebate rate. Fee2 is a score from 1 to 10 created by Markit using their proprietary information meant to capture the cost of borrowing the stock. Here 1 is the cheapest to short and 10 the most difficult. Fee1 is available since November of 2006 while fee2 is available since October of 2003. SIO is short interest ratio (SR) divided by institutional ownership. All the t-statistics are Newey and West (1987) adjusted to control for heteroskedasticity and autocorrelation. $* * *, * *$, and $*$ stands for significance level of $1 \%, 5 \%$ and $10 \%$, respectively.

\begin{tabular}{|c|c|c|c|c|c|c|c|c|c|}
\hline & (1) & (2) & $(3)$ & (4) & (5) & (6) & (7) & (8) & (9) \\
\hline \multirow[t]{2}{*}{ SR } & -0.0338 & & -0.0047 & -0.0251 & & -0.0013 & -0.0263 & & 0.0048 \\
\hline & $(-1.01)$ & & $(-0.14)$ & $(-1.56)$ & & $(-0.08)$ & $(-1.12)$ & & $(0.16)$ \\
\hline \multirow[t]{2}{*}{ DTC } & & $-0.0003^{*}$ & $-0.0003^{* *}$ & & $-0.0003^{* * *}$ & $-0.0003^{* *}$ & & $-0.0002^{* * *}$ & $-0.0002^{* * *}$ \\
\hline & & $(-1.71)$ & $(-2.48)$ & & $(-2.86)$ & $(-2.47)$ & & $(-4.05)$ & $(-3.34)$ \\
\hline \multirow[t]{2}{*}{ Beta } & 0.0023 & 0.0022 & 0.0022 & 0.0027 & 0.0024 & 0.0024 & 0.0012 & 0.0011 & 0.0011 \\
\hline & $(0.78)$ & $(0.77)$ & $(0.76)$ & (1.13) & $(1.02)$ & $(1.05)$ & $(0.88)$ & $(0.80)$ & $(0.80)$ \\
\hline \multirow[t]{2}{*}{ LnME } & -0.0005 & -0.0005 & -0.0006 & $-0.0011^{* *}$ & $-0.0012^{* *}$ & $-0.0012^{* *}$ & $-0.0010^{* *}$ & $-0.0010^{* *}$ & $-0.0011^{* *}$ \\
\hline & $(-0.78)$ & $(-0.77)$ & $(-0.87)$ & $(-2.03)$ & $(-2.08)$ & $(-2.14)$ & $(-2.27)$ & $(-2.31)$ & $(-2.34)$ \\
\hline \multirow[t]{2}{*}{ LnBM } & -0.0011 & -0.0012 & -0.0012 & 0.0006 & 0.0008 & 0.0007 & $0.0020 * * *$ & $0.0021 * * *$ & $0.0021^{* * *}$ \\
\hline & $(-0.88)$ & $(-0.97)$ & $(-0.95)$ & $(0.62)$ & $(0.77)$ & $(0.69)$ & $(2.74)$ & $(2.82)$ & $(2.83)$ \\
\hline \multirow[t]{2}{*}{ Rev } & $-0.0258^{*}$ & $-0.0238^{*}$ & $-0.0260^{*}$ & $-0.0358^{* * *}$ & $-0.0360 * * *$ & $-0.0357^{* * *}$ & $-0.0508^{* * *}$ & $-0.0507^{* * *}$ & $-0.0507^{* * *}$ \\
\hline & $(-1.81)$ & $(-1.71)$ & $(-1.82)$ & $(-4.98)$ & $(-4.94)$ & $(-4.92)$ & $(-12.48)$ & $(-12.44)$ & $(-12.47)$ \\
\hline \multirow[t]{2}{*}{ Mom } & -0.0046 & -0.0047 & -0.0047 & -0.0027 & -0.0029 & -0.0028 & $0.0038^{* *}$ & $0.0036^{* *}$ & $0.0037^{* *}$ \\
\hline & $(-0.71)$ & $(-0.71)$ & $(-0.72)$ & $(-0.65)$ & $(-0.70)$ & $(-0.69)$ & $(2.13)$ & $(2.06)$ & $(2.05)$ \\
\hline \multirow[t]{2}{*}{ Fee1 } & 0.0000 & 0.0000 & 0.0000 & & & & & & \\
\hline & $(0.43)$ & $(0.37)$ & $(0.24)$ & & & & & & \\
\hline Fee2 & & & & $\begin{array}{c}-0.0027^{* * *} \\
(-3.81)\end{array}$ & $\begin{array}{c}-0.0025^{* * *} \\
(-3.40)\end{array}$ & $\begin{array}{c}-0.0025^{* * *} \\
(-3.62)\end{array}$ & & & \\
\hline $\mathrm{SIO}$ & & & & & & & $\begin{array}{c}-0.0186^{* * *} \\
(-7.25)\end{array}$ & $\begin{array}{c}-0.0142^{* * *} \\
(-5.34)\end{array}$ & $\begin{array}{c}-0.0157^{* * *} \\
(-5.64)\end{array}$ \\
\hline Ave.R-sq & 0.088 & 0.086 & 0.090 & 0.050 & 0.050 & 0.053 & 0.056 & 0.055 & 0.058 \\
\hline N.of Obs. & 102980 & 102980 & 102980 & 289026 & 289026 & 289026 & 987678 & 987678 & 987678 \\
\hline
\end{tabular}




\section{Table 7: Fama-MacBeth Regressions of Monthly Returns on SR and DTC - Log Specification}

This table reports results from Fama-Macbeth (1973) regression of monthly stock returns on $\log (\mathrm{SR})$ and/or $\log (\mathrm{DTC}) . \log (\mathrm{SR})$ is the natural $\log$ of short interest ratio (SR), which is the shares shorted over total shares outstanding. $\log (\mathrm{DTC})$ is the natural $\log$ of Days-to-cover (DTC) measure, which is short interest ratio (SR) over daily turnover. Market beta (Beta) is calculated from past five years' monthly return, following Fama and French (1992). Size (LnME) is the natural log of firm market capitalization at the end of the June of each year. Book-to-market (LnBM) is the natural log of book-to-market ratio. The cases with negative book value are deleted. Momentum (MOM) is defined as the cumulative return from month $\mathrm{t}-12$ to $\mathrm{t}-2$. The short term reversal measure (REV) is the lagged monthly return. All t-statistics are based on Newey and West (1987) with 4 lags to control for heteroskedasticity and autocorrelation. ${ }^{* * *},{ }^{* *}$, and ${ }^{*}$ stands for significance level of $1 \%, 5 \%$ and $10 \%$, respectively.

\begin{tabular}{cccc}
\hline & $(1)$ & $(2)$ & $(3)$ \\
\hline $\log (\mathrm{SR})$ & $-0.0006^{* * *}$ & & $0.0015^{*}$ \\
& $(-2.74)$ & $-0.0011^{* * *}$ & $(1.96)$ \\
$\log (\mathrm{DTC})$ & & $(-5.54)$ & $-0.0025^{* * *}$ \\
& & 0.0022 & $(-3.69)$ \\
Beta & 0.0023 & $(1.40)$ & 0.0016 \\
& $(1.51)$ & -0.0000 & $(1.14)$ \\
LnME & -0.0000 & $(-0.07)$ & -0.0005 \\
& $(-0.09)$ & $0.0024^{* * *}$ & $(-0.84)$ \\
LnBM & $0.0024^{* * *}$ & $(2.86)$ & $0.0025^{* * *}$ \\
& $(2.91)$ & $-0.0367^{* * *}$ & $(3.15)$ \\
Rev & $-0.0360^{* * *}$ & $(-8.91)$ & $-0.0372^{* * *}$ \\
& $(-8.72)$ & $0.0045^{* *}$ & $(-9.04)$ \\
Mom & $0.0047^{* * *}$ & $(2.50)$ & $0.0043^{* *}$ \\
& $(2.62)$ & 0.048 & $(2.30)$ \\
Ave.R-sq & 0.050 & 906377 & 0.054 \\
N.of Obs. & 906377 & & 906377 \\
\hline \hline
\end{tabular}




\section{Table 8: Fama-MacBeth Regressions of Monthly Returns on SR and DTC - Al- ternative DTC Measures}

This table reports results from Fama-Macbeth (1973) regression of monthly stock returns on SR and alternative DTC measures. Short interest ratio (SR) is the shares shorted over total shares outstanding. DTC2 is short interest ratio (SR) over average daily turnover measured over prior month. DTC3 is short interest ratio (SR) over average daily turnover measured over past six months. DTC4 is short interest ratio (SR) over average daily turnover measured over past twelve months. Market beta (Beta) is calculated from past five years' monthly return, following Fama and French (1992). Size (LnME) is the natural log of firm market capitalization at the end of the June of each year. Book-to-market (LnBM) is the natural log of book-to-market ratio. The cases with negative book value are deleted. Momentum (MOM) is defined as the cumulative return from month $\mathrm{t}-12$ to $\mathrm{t}-2$. The short term reversal (REV) is the lagged monthly return. Fee2 is a score from 1 to 10 created by Markit using their proprietary information meant to capture the cost of borrowing the stock. Here 1 is the cheapest to short and 10 the most difficult. Fee2 is available since October of 2003. All the t-statistics are Newey and West (1987) adjusted to control for heteroskedasticity and autocorrelation. ${ }^{* * *},{ }^{* *}$, and ${ }^{*}$ stands for significance level of $1 \%, 5 \%$ and $10 \%$, respectively.

\begin{tabular}{cccc}
\hline & $(1)$ & $(2)$ & $(3)$ \\
\hline SR & -0.0033 & -0.0026 & 0.0017 \\
DTC2 & $(-0.23)$ & $(-0.18)$ & $(0.10)$ \\
& $-0.0003^{*}$ & & \\
DTC3 & $(-1.82)$ & $-0.0005^{*}$ & \\
& & $(-1.85)$ & \\
DTC4 & & & $-0.0005^{*}$ \\
& & & $(-1.84)$ \\
Beta & 0.0025 & 0.0026 & 0.0032 \\
& $(1.07)$ & $(1.09)$ & $(1.25)$ \\
LnME & -0.0002 & -0.0002 & -0.0002 \\
& $(-0.36)$ & $(-0.52)$ & $(-0.56)$ \\
LnBM & 0.0006 & 0.0006 & 0.0006 \\
& $(0.62)$ & $(0.58)$ & $(0.61)$ \\
Rev & $-0.0354^{* * *}$ & $-0.0353^{* * *}$ & $-0.0267^{* * *}$ \\
& $(-4.90)$ & $(-4.86)$ & $(-3.79)$ \\
Mom & -0.0006 & -0.0005 & -0.0004 \\
& $(-0.16)$ & $(-0.14)$ & $(-0.10)$ \\
Fee2 & $-0.0027^{* * *}$ & $-0.0027^{* * *}$ & $-0.0026^{* * *}$ \\
& $(-3.98)$ & $(-3.99)$ & $(-5.04)$ \\
Ave.R-sq & 0.056 & 0.057 & 0.051 \\
N.of Obs. & 289026 & 289026 & 289026 \\
\hline \hline
\end{tabular}




\section{Table 9: Fama-MacBeth Regressions of Monthly Returns on SR and DTC - Ro-}

\section{bustness}

This table shows results from Fama-Macbeth (1973) regression for various robustness checks. Days-to-cover (DTC) is short interest ratio (SR) over daily turnover. DTC2 is short interest ratio (SR) over average daily turnover measured over prior month. DTC3 is short interest ratio (SR) over average daily turnover measured over past six months. DTC4 is short interest ratio (SR) over average daily turnover measured over past twelve months. Market beta (Beta) is calculated from past five years' monthly return, following Fama and French (1992). Size (LnME) is the natural log of firm market capitalization at the end of the June of each year. Book-to-market (LnBM) is the natural log of book-to-market ratio. The cases with negative book value are deleted. Momentum (MOM) is defined as the cumulative return from month t-12 to t-2. The short term reversal (REV) is the lagged monthly return. Amihud_illiq is the Amihud (2002)'s illiquidity measure. 1 /Turnover is one divided by daily turnover ratio. 1 /Turnover 2 is one divided by average daily turnover measured over prior month. 1 /Turnover3 is one divided by average daily turnover measured over past six months. 1/Turnover4 is one divided by average daily turnover measured over past twelve months. IVOL is the idiosyncratic volatility, calculated following Ang et al. (2006). Dispersion (DISP) is the analysts' earnings forecast dispersion measure, following Diether, Malloy and Scherbina (2002). All the t-statistics are Newey and West (1987) adjusted to control for heteroskedasticity and autocorrelation. ***, $* *$, and ${ }^{*}$ stands for significance level of $1 \%, 5 \%$ and $10 \%$, respectively.

\begin{tabular}{|c|c|c|c|c|c|c|c|c|}
\hline & $(1)$ & $(2)$ & (3) & (4) & (5) & $(6)$ & $(7)$ & $(8)$ \\
\hline DTC & $\begin{array}{c}-0.0004^{* * *} \\
(-8.96)\end{array}$ & & & & & & $\begin{array}{c}-0.0004^{* * *} \\
(-9.87)\end{array}$ & $\begin{array}{c}-0.0006^{* * *} \\
(-4.12)\end{array}$ \\
\hline 1/Turnover & $\begin{array}{c}-0.0000^{* * *} \\
(-3.17)\end{array}$ & & & & & & & \\
\hline DTC2 & & $\begin{array}{c}-0.0003^{* * *} \\
(-6.38)\end{array}$ & & & & & & \\
\hline 1/Turnover2 & & $\begin{array}{c}-0.0000 \\
(-1.42)\end{array}$ & & & & & & \\
\hline DTC3 & & & $\begin{array}{c}-0.0004^{* * *} \\
(-7.20)\end{array}$ & & $\begin{array}{c}-0.0003^{* * *} \\
(-6.90)\end{array}$ & & & \\
\hline 1/Turnover3 & & & & & $\begin{array}{c}-0.0000^{*} \\
(-1.71)\end{array}$ & & & \\
\hline DTC4 & & & & $\begin{array}{c}-0.0004^{* * *} \\
(-6.28)\end{array}$ & & $\begin{array}{c}-0.0003^{* * *} \\
(-6.00)\end{array}$ & & \\
\hline 1/Turnover4 & & & & & & $\begin{array}{c}-0.0000 \\
(-1.03)\end{array}$ & & \\
\hline Amihud_illiq & & & $\begin{array}{c}0.0000 \\
(0.23)\end{array}$ & $\begin{array}{c}0.0000 \\
(0.24)\end{array}$ & & & & \\
\hline LnME & $\begin{array}{c}-0.0005 \\
(-0.87)\end{array}$ & $\begin{array}{c}-0.0003 \\
(-0.59)\end{array}$ & $\begin{array}{c}-0.0003 \\
(-0.56)\end{array}$ & $\begin{array}{c}-0.0003 \\
(-0.54)\end{array}$ & $\begin{array}{c}-0.0003 \\
(-0.55)\end{array}$ & $\begin{array}{c}-0.0002 \\
(-0.41)\end{array}$ & $\begin{array}{c}-0.0008^{*} \\
(-1.93)\end{array}$ & $\begin{array}{c}-0.0010^{*} \\
(-1.80)\end{array}$ \\
\hline LnBM & $\begin{array}{c}0.0029^{* * *} \\
(3.50)\end{array}$ & $\begin{array}{c}0.0029 * * * \\
(3.45)\end{array}$ & $\begin{array}{c}0.0027^{* * *} \\
(3.08)\end{array}$ & $\begin{array}{c}0.0027^{* * *} \\
(3.09)\end{array}$ & $\begin{array}{c}0.0028^{* * *} \\
(3.40)\end{array}$ & $\begin{array}{c}0.0028^{* * *} \\
(3.34)\end{array}$ & $\begin{array}{c}0.0023^{* * *} \\
(2.83)\end{array}$ & $\begin{array}{c}0.0014 \\
(1.44)\end{array}$ \\
\hline Rev & $\begin{array}{c}-0.0331^{* * *} \\
(-8.61)\end{array}$ & $\begin{array}{c}-0.0321^{* * *} \\
(-8.32)\end{array}$ & $\begin{array}{c}-0.0315^{* * *} \\
(-7.97)\end{array}$ & $\begin{array}{c}-0.0314^{* * *} \\
(-7.94)\end{array}$ & $\begin{array}{c}-0.0322^{* * *} \\
(-8.33)\end{array}$ & $\begin{array}{c}-0.0321^{* * *} \\
(-8.31)\end{array}$ & $\begin{array}{c}-0.0315^{* * *} \\
(-7.67)\end{array}$ & $\begin{array}{c}-0.0278^{* * *} \\
(-5.74)\end{array}$ \\
\hline Mom & $\begin{array}{c}0.0037^{* *} \\
(2.07)\end{array}$ & $\begin{array}{c}0.0038^{* *} \\
(2.15)\end{array}$ & $\begin{array}{c}0.0036^{* *} \\
(2.05)\end{array}$ & $\begin{array}{c}0.0038^{* *} \\
(2.15)\end{array}$ & $\begin{array}{c}0.0038^{* *} \\
(2.18)\end{array}$ & $\begin{array}{c}0.0040^{* *} \\
(2.28)\end{array}$ & $\begin{array}{c}0.0033^{*} \\
(1.91)\end{array}$ & $\begin{array}{c}0.0005 \\
(0.12)\end{array}$ \\
\hline IVOL & & & & & & & $\begin{array}{c}-0.1188^{* * *} \\
(-3.10)\end{array}$ & \\
\hline DISP & & & & & & & & $\begin{array}{r}0.0017 \\
(0.80)\end{array}$ \\
\hline Constant & $\begin{array}{c}0.0131^{* * *} \\
(2.91)\end{array}$ & $\begin{array}{c}0.0108^{* *} \\
(2.38)\end{array}$ & $\begin{array}{c}0.0108^{* *} \\
(2.48)\end{array}$ & $\begin{array}{c}0.0106^{* *} \\
(2.43)\end{array}$ & $\begin{array}{c}0.0112^{* *} \\
(2.37)\end{array}$ & $\begin{array}{c}0.0103^{* *} \\
(2.14)\end{array}$ & $\begin{array}{c}0.0156^{* * *} \\
\quad(4.70)\end{array}$ & $\begin{array}{c}0.0155^{* * *} \\
(3.15)\end{array}$ \\
\hline Ave.R-sq & 0.047 & 0.047 & 0.047 & 0.047 & 0.048 & 0.048 & 0.050 & 0.071 \\
\hline N.of Obs. & 1041563 & 1041563 & 974842 & 974823 & 1041563 & 1041540 & 1003934 & 627762 \\
\hline
\end{tabular}

